\title{
Molecular dynamics correctly models the unusual major conformation of the GAGU RNA internal loop and with NMR reveals an unusual minor conformation
}

\author{
ALEKSANDAR SPASIC, ${ }^{1,2,7}$ SCOTT D. KENNEDY, ${ }^{1,7}$ LAURA NEEDHAM, ${ }^{1,2}$ MUTHIAH MANOHARAN, ${ }^{3}$ \\ RYSZARD KIERZEK, ${ }^{4}$ DOUGLAS H. TURNER, ${ }^{2,5}$ and DAVID H. MATHEWS ${ }^{1,2,6}$ \\ ${ }^{1}$ Department of Biochemistry and Biophysics, University of Rochester Medical Center, Rochester, New York 14642, USA \\ ${ }^{2}$ Center for RNA Biology, University of Rochester Medical Center, Rochester, New York 14642, USA \\ ${ }^{3}$ Department of Discovery, Alnylam Pharmaceuticals, Cambridge, Massachusetts 02142, USA \\ ${ }^{4}$ Institute of Bioorganic Chemistry, Polish Academy of Sciences, 61-704 Poznan Noskowskiego, Poland \\ ${ }^{5}$ Department of Chemistry, University of Rochester, Rochester, New York 14627-0216, USA \\ ${ }^{6}$ Department of Biostatistics and Computational Biology, University of Rochester Medical Center, Rochester, New York 14642, USA
}

\begin{abstract}
The RNA "GAGU" duplex, (5'GACGAGUGUCA $)_{2}$, contains the internal loop $\left(5^{\prime}-\mathrm{GAGU}-3^{\prime}\right)_{2}$, which has two conformations in solution as determined by NMR spectroscopy. The major conformation has a loop structure consisting of trans-Watson-Crick/ Hoogsteen GG pairs, A residues stacked on each other, $U$ residues bulged outside the helix, and all sugars with a C2'-endo conformation. This differs markedly from the internal loops, $\left(5^{\prime}\right.$-GAGC-3 ${ }_{2}^{\prime},\left(5^{\prime} \text {-AAGU-3 }\right)_{2}$, and $\left(5^{\prime} \text {-UAGG-3 }\right)_{2}$, which all have cis-Watson-Crick/Watson-Crick AG "imino" pairs flanked by cis-Watson-Crick/Watson-Crick canonical pairs resulting in maximal hydrogen bonding. Here, molecular dynamics was used to test whether the Amber force field (ff99+bsc0+ OL3) approximates molecular interactions well enough to keep stable the unexpected conformation of the GAGU major duplex structure and the NMR structures of the duplexes containing $\left(5^{\prime}-\mathrm{GAGC}-3^{\prime}\right)_{2},\left(5^{\prime}-\mathrm{AAGU}-3^{\prime}\right)_{2}$, and $\left(5^{\prime}-\mathrm{UAGG}-3^{\prime}\right)_{2}$ internal loops. One-microsecond simulations were repeated four times for each of the duplexes starting in their NMR conformations. With the exception of $\left(5^{\prime} \text {-UAGG-3' }\right)_{2}$, equivalent simulations were also run starting with alternative conformations. Results indicate that the Amber force field keeps the NMR conformations of the duplexes stable for at least 1 usec. They also demonstrate an unexpected minor conformation for the $\left(5^{\prime}-\mathrm{GAGU}-3^{\prime}\right)_{2}$ loop that is consistent with newly measured NMR spectra of duplexes with natural and modified nucleotides. Thus, unrestrained simulations led to the determination of the previously unknown minor conformation. The stability of the native $\left(5^{\prime}-\mathrm{GAGU}-3^{\prime}\right)_{2}$ internal loop as compared to other loops can be explained by changes in hydrogen bonding and stacking as the flanking bases are changed.
\end{abstract}

Keywords: molecular dynamics; RNA internal loop; Amber; GAGU

\section{INTRODUCTION}

RNA performs many important roles, such as storing genetic information, catalysis, and regulating gene expression (Eddy 2001; Doudna and Cech 2002; Altman 2007; Serganov and Patel 2007; Wu and Belasco 2008; Atkins et al. 2011). Many families of RNA have a conserved 3D structure that dictates function (Pley et al. 1994; Cate et al. 1996; Verschoor et al. 1998; Ban et al. 2000; Yusupov et al. 2001; Adams et al. 2004; Amunts et al. 2014). Therefore, understanding and being able to model the interactions that stabilize structure is important. Blind tests of prediction of 3D

\footnotetext{
${ }^{7}$ These authors contributed equally to this work.

Corresponding authors: david_mathews@urmc.rochester.edu, douglas.turner@rochester.edu

Article is online at http://www.rnajournal.org/cgi/doi/10.1261/rna 064527.117
}

structure from sequence have revealed that local structure in loops is difficult to predict accurately (Miao et al. 2015, 2017). In principle, given a secondary structure, molecular dynamics (MD) with an accurate force field should be able to predict the 3D structures of component loops. Here, we test the ability of the Amber force field ff $99+$ bsc0 + OL3 (Cornell et al. 1995; Cheatham et al. 1999; Pérez et al. 2007; Zgarbová et al. 2011; Case et al. 2012) (see Table 1 for a list of abbreviations) to model known structures of $2 \times 2 \mathrm{nt}$ internal loops with tandem AG pairs.

The internal loop motif, $\left(5^{\prime}-\mathrm{GA}-3^{\prime}\right)_{2}$, comprises $20 \%$ of $2 \times 2 \mathrm{nt}$ internal loops in a database of 1899 secondary

(C) 2018 Spasic et al. This article is distributed exclusively by the RNA Society for the first 12 months after the full-issue publication date (see http://rnajournal.cshlp.org/site/misc/terms.xhtml). After 12 months, it is available under a Creative Commons License (Attribution-NonCommercial 4.0 International), as described at http://creativecommons.org/licenses/by-nc/4.0/. 
TABLE 1. List of abbreviations

\begin{tabular}{|c|c|}
\hline $2^{\prime} \mathrm{F}$ & Ribose $2^{\prime} \mathrm{OH}$ replaced with $2^{\prime} \mathrm{F}$ (see Fig. 9 for positions). \\
\hline Amber force field ff $99+\mathrm{bsc} 0+\mathrm{OL} 3$ & $\begin{array}{l}\text { The Amber ff99 force field (Cornell et al. 1995; Cheatham et al. 1999) with the corrections for } \alpha, \gamma \\
\text { (Pérez et al. 2007), and } \chi \text { (Zgarbová et al. 2011) dihedrals. This is the current recommended Amber } \\
\text { force field for RNA simulations. }\end{array}$ \\
\hline Bulged conformation & NMR (bulged) structure for GAGU duplex or alternative (bulged) structure for other duplexes (Fig. 3). \\
\hline I, $4 \mathrm{I}, 6 \mathrm{I}$ & G replaced by inosine (see Fig. 9 for positions). \\
\hline G4\&G6 $\mathrm{NH}_{2} \mathrm{H}$-bonded & Loop with $\mathrm{H}$-bonding shown in Figure 7 centroid structure. \\
\hline $\mathrm{G} 6 \mathrm{~m}, \mathrm{~A} 5^{*} \mathrm{~m}$, etc. & (m) Minor conformation \\
\hline & $\left(^{*}\right)$ Opposite strand nucleotide \\
\hline LNA & Ribose modified to have $\mathrm{CH}_{2}$ bridging $\mathrm{O}^{\prime}$ and $\mathrm{C}^{\prime}$. \\
\hline Maximally $\mathrm{H}$-bonded & Loop with imino AG pairs flanked by Watson-Crick or wobble GU pairs (Figs. 3 and 7 starting structures). \\
\hline
\end{tabular}

structures (Christiansen and Znosko 2008). NMR structures of such loops symmetrically closed by GC, CG, AU, UA, or GU pairs have also been determined (Santa Lucia and Turner 1993; Wu and Turner 1996; Heus et al. 1997; Tolbert et al. 2007). When both closing base pairs are CG, AU, UA, UG, or GU, e.g., $\left(5^{\prime}\right.$-GGAU-3') ${ }^{\prime}$, transHoogsteen/sugar edge GA (sheared) pairs form. The internal loop, $\left(5^{\prime} \text {-GGAC-3' }\right)_{2}$, however, has cis-Watson-Crick/ Watson-Crick GC and GA (imino) pairs. Computational studies on these systems (Yildirim et al. 2009; Morgado et al. 2012; Aytenfisu et al. 2014) pointed toward stacking and out-of-plane $\mathrm{G}$ amino group $\mathrm{H}$-bonds as stabilizing the cis-Watson-Crick/Watson-Crick GA pairs.

The internal loop motif, $\left(5^{\prime}-\mathrm{AG}-3^{\prime}\right)_{2}$, comprises $<0.5 \%$ of the $2 \times 2$ nt loop database (Christiansen and Znosko 2008) and is not found in the RNA FRABASE of crystal structures (Popenda et al. 2010). It is proposed, however, in the context of $5^{\prime} \mathrm{UAGG} / 3^{\prime} \mathrm{AGAC}$, in a Group II ribozyme (Marcia and Pyle 2012; Chan et al. 2012; Zhao et al. 2015) and in $5^{\prime}$ GAGU/3'CGAG in the SOLE element of oskar mRNA (Simon et al. 2015). To better understand the interactions providing thermodynamic stabilities of RNA duplexes containing $2 \times 2$ nt tandem symmetrical internal loops, NMR structures of six sequences with $\left(5^{\prime}-\mathrm{AG}-3^{\prime}\right)_{2}$ internal loops flanked by different base pairs have been determined ( $\mathrm{Wu}$ et al. 1997; Hammond et al. 2010; Kennedy et al. 2012). The $\left(5^{\prime}-\mathrm{GAGC}-3^{\prime}\right)_{2},\left(5^{\prime}-\mathrm{AAGU}-3^{\prime}\right)_{2},\left(5^{\prime}-\mathrm{UAGG}-3^{\prime}\right)_{2}$, (5'-UAGA$\left.3^{\prime}\right)_{2}$, and $\left(5^{\prime}-\mathrm{CAGG}-\overline{\left.3^{\prime}\right)_{2}}\right.$ internal loops each form a conformation where hydrogen bonding is maximized, i.e., cisWatson-Crick/Watson-Crick AG (imino) noncanonical pairs are formed and flanked by Watson-Crick or wobble GU base pairs. Surprisingly, the $\left(5^{\prime}-\mathrm{GAGU}-3^{\prime}\right)_{2}$ internal loop forms two conformations of which the major one has two trans-Watson-Crick/Hoogsteen GG pairs, two A residues stacked on each other, $U$ residues bulged outside the helix and all sugars in a $\mathrm{C} 2^{\prime}$-endo conformation (Table 2; Figs. 1-3).

To our knowledge, no molecular mechanics analysis has been performed for the $\left(5^{\prime}-\mathrm{AG}-3^{\prime}\right)_{2}$ internal loops. In this work, $\mathrm{MD}$ simulations were used to compare the simulated stabilities of NMR structures of the $\left(5^{\prime}-\mathrm{AG}-3^{\prime}\right)_{2}$ internal loop flanked by four different closing pairs (Fig. 3). There were two initial goals. First, to test the ability of Amber force field ff99 (Cornell et al. 1995; Cheatham et al. 1999) and current Amber force field (ff99 + bsc0 + OL3) (Cornell et al. 1995; Cheatham et al. 1999; Pérez et al. 2007; Zgarbová et al. 2011; Case et al. 2012) to properly model the interactions responsible for stability of these structures. Second, to provide reasons for the unusual conformational preference of the $\left(5^{\prime}-\mathrm{GAGU}-3^{\prime}\right)_{2}$ internal loop. An unexpected result was prediction of details of the minor conformation(s) of

TABLE 2. Structural characteristics of sequences used in this study

\begin{tabular}{lcl}
\hline Sequence & Loop region & \multicolumn{1}{c}{ Loop pairing } \\
\hline $5^{\prime}$-GACGAGUGUCA & GAGU & GG trans-WC/Hoogsteen with syn glycosidic bonds \\
ACUGUGAGCAG-5' & C2'-endo puckers \\
& & AA stack, U flipped out \\
\hline $5^{\prime}$-GACGAGCGUCA & GAGC & \\
ACUGCGAGCAG-5' & CGAG & AG cis-WC/WC (imino) \\
5'-GACAAGUGUCA & AGU & C3'-endo pucker \\
ACUGUGAACAG-5' & canonical (GC, AU, or UG) base pairs close loop \\
$5^{\prime}$-GGUAGGCCA & UAGG & \\
ACCGGAUGG-5' & GGAU & \\
\hline
\end{tabular}

Loop nucleotides are underlined and the closing base pairs are shown in bold. Note that sequences with GAGU, GAGC, and AAGU loop regions differ only in base pairs that close the loop, while the UAGG sequence is a shorter sequence with different base pair composition. 

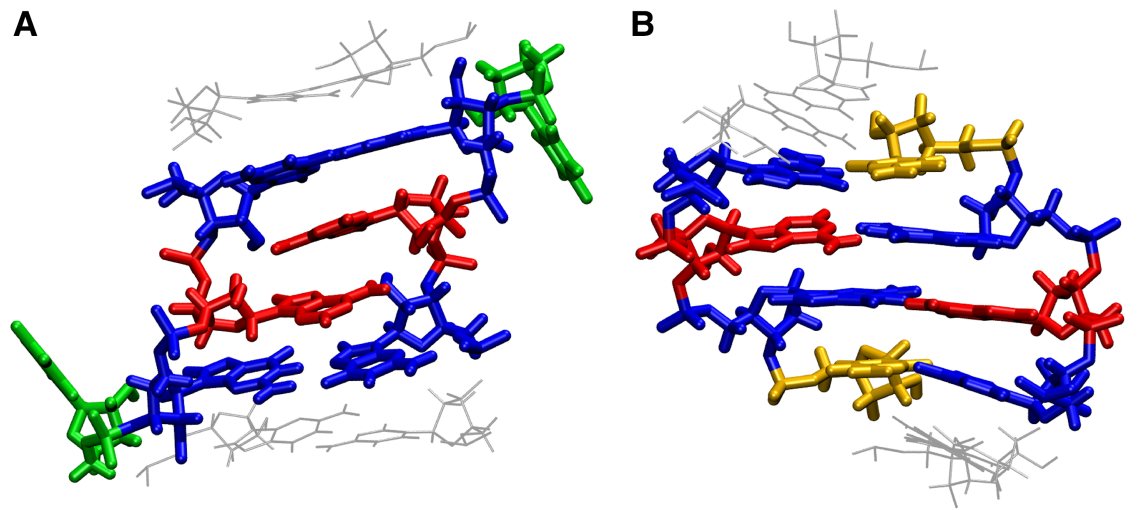

FIGURE 1. Structure of loop and closing base pair of the two types of conformations studied in this work. (A) GAGU major NMR conformation and (B) GAGC NMR conformation (AAGU and UAGG have the same loop structure as GAGC). The types of hydrogen bonding are listed in Table 2. Guanines are colored in blue, adenines in red, uracil in green, and cytosine in yellow.

the $\left(5^{\prime}-\mathrm{GAGU}-3^{\prime}\right)_{2}$ internal loop that inspired new measurements and interpretation of NMR spectra of the unmodified GAGU duplex and of several modified with inosine, or purine, or LNA, or 2'F sugars.

To accomplish the above goals, alternative conformations for three duplexes were also created (Fig. 3) and studied along with the NMR conformations. Specifically, a (5'GAGC-3' $)_{2}$-like conformation that maximizes hydrogen bonding was created for the GAGU duplex, and a (5'GAGU-3') ${ }_{2}$-like bulged conformation was created for the GAGC and AAGU duplexes (see Table 1; Fig. 3 for abbreviations). The UAGG duplex was only studied in its NMR con- formation (Fig. 3) because of its different length and the difficulty of manually transforming a purine into a pyrimidine nucleotide. The upper panel of Figure 3 depicts the NMR conformations and the lower panel depicts alternative conformations. Alternative conformations provide insight into atomic features that favor the unusual $\left(5^{\prime}-\mathrm{GAGU}-3^{\prime}\right)_{2}$ major conformation. The modeled $\left(5^{\prime}-\right.$ GAGU- $\left.3^{\prime}\right)_{2}$-like conformation of the duplex with the GAGC sequence differs from the GAGU duplex only in that it has cytosine residues bulged out instead of uracils. On the other hand, the modeled ( $5^{\prime}$-GAGU- $\left.3^{\prime}\right)_{2}$-like (bulged) conformation of the duplex with the AAGU sequence has uracils bulged out, but the duplex requires an AG pair instead of a GG pair. Four 1- $\mu$ sec-long simulations were run for each starting conformation of each sequence. The simulations reveal that the current Amber force field correctly reproduces the experimental observations that the NMR conformations are more stable than the alternative conformations. Further analysis suggests that the unusual conformational preference for $\left(5^{\prime}-\mathrm{GAGU}-3^{\prime}\right)_{2}$ lies in the combination of steric, hydrogen bonding, and stacking interactions. Additionally, simulations starting with the maximally $\mathrm{H}$-bonded conformation for $\left(5^{\prime} \text {-GAGU- } 3^{\prime}\right)_{2}$ suggest an unusual minor conformation that is consistent with newly measured NMR spectra.
A

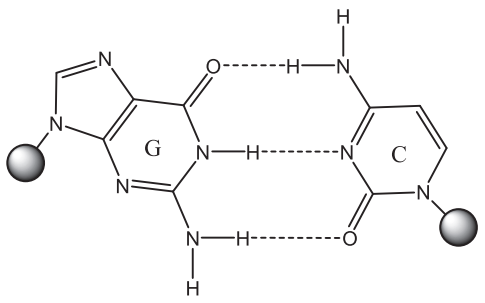

D

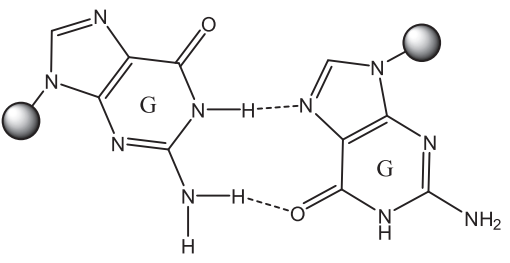

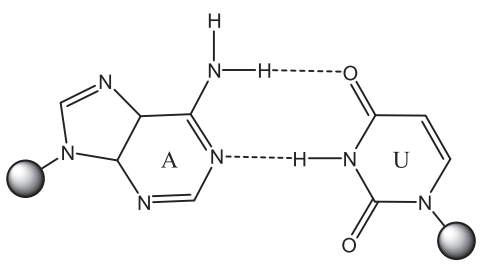

E

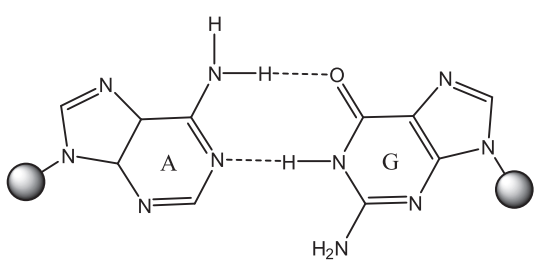

C

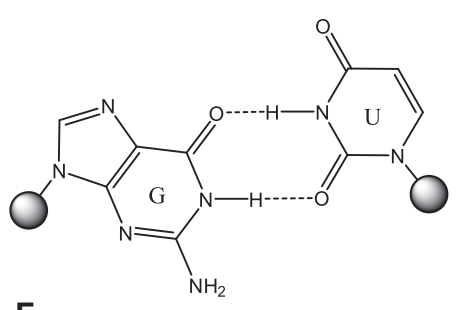

$\mathbf{F}$

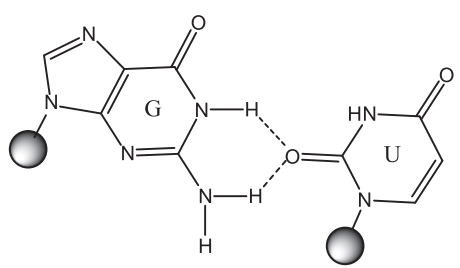

FIGURE 2. Base-pairings of studied sequences. (A) Canonical cis-Watson-Crick/Watson-Crick GC pair closing the NMR conformation of $\left(5^{\prime}\right.$ GAGC- $\left.3^{\prime}\right)_{2}$ internal loop. (B) Canonical cis-Watson-Crick/Watson-Crick AU pair closing the NMR conformation of $\left(5^{\prime} \text {-AAGU-3' }\right)_{2}$ internal loop. (C) Canonical cis-Watson-Crick/Watson-Crick (wobble) GU pair closing the NMR conformation of $\left(5^{\prime}-\mathrm{UAGG}-3^{\prime}\right)_{2}$ internal loop and alternative maximally $\mathrm{H}$-bonded conformation of $\left(5^{\prime} \text {-GAGU-3' }\right)_{2}$. (D) trans-Watson-Crick/Hoogsteen GG pair in the loop of $\left(5^{\prime}-\mathrm{GAGU}-3^{\prime}\right)_{2}$ NMR (bulged) conformation; both $\mathrm{G}^{\prime}$ s are syn. (E) cis-Watson-Crick/Watson-Crick (imino) AG pair in the loop of alternative (maximally H-bonded) conformation of $\left(5^{\prime} \text {-GAGU- } 3^{\prime}\right)_{2}$ and NMR conformations of $\left(5^{\prime} \text {-GAGC- } 3^{\prime}\right)_{2}$, $\left(5^{\prime} \text {-AAGU-3' }\right)_{2}$, and $\left(5^{\prime} \text {-UAGG-3' }\right)_{2}$. $(F)$ cisWatson-Crick/Sugar edge GU pair stabilizing the centroid of simulation observed starting with $\left(5^{\prime} \text {-GAGU- } 3^{\prime}\right)_{2}$ alternative (maximally H-bonded) structure. 


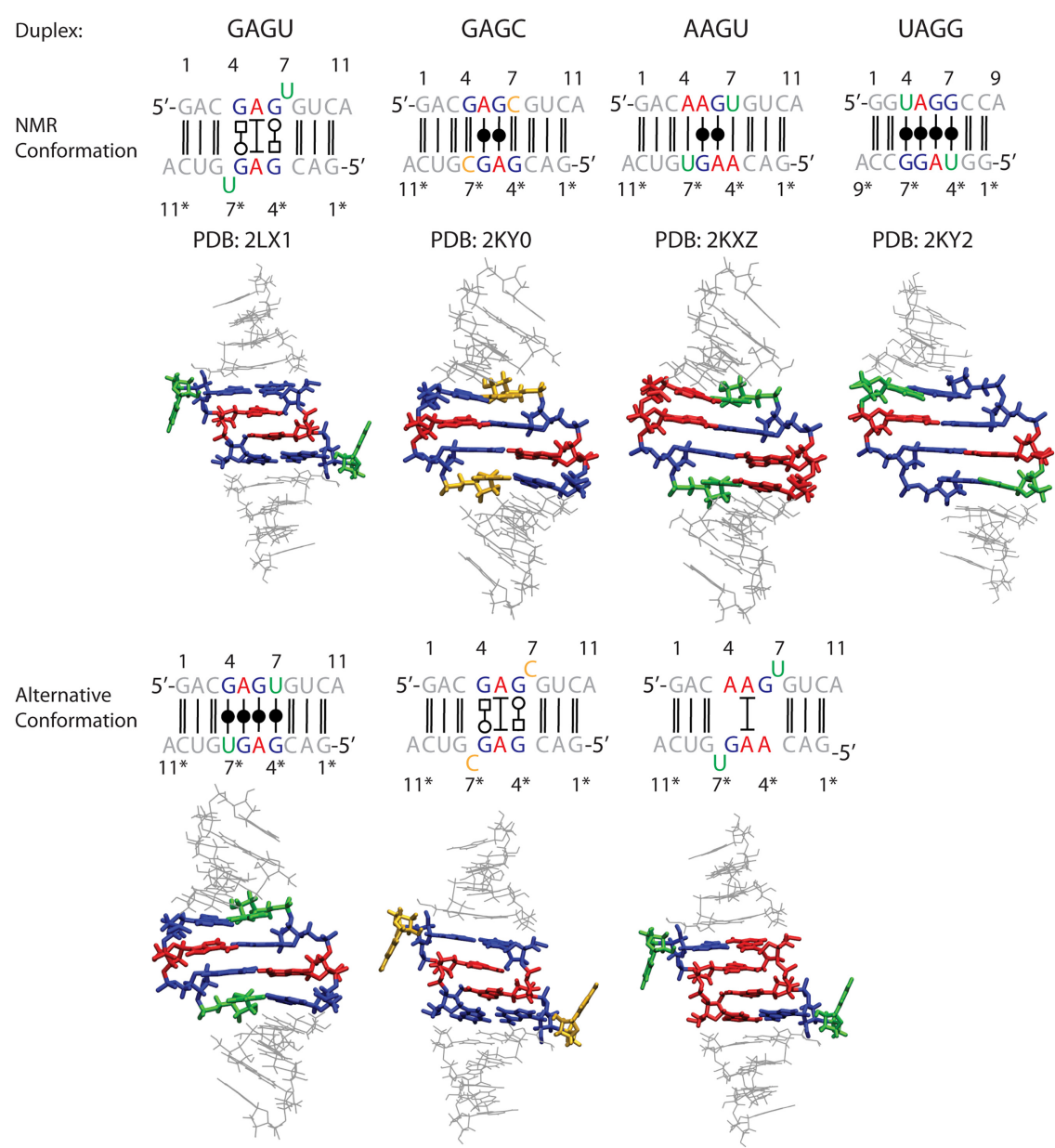

FIGURE 3. Sequences (top) and starting conformations of simulated duplexes. Upper and lower conformations, respectively, correspond to NMR determined structures and structures of alternative conformations created using the procedure outlined in Materials and Methods. Guanine residues are colored blue, adenine red, uracil green, and cytosine yellow. Nucleotides in the sequences of complementary strands are labeled with $\left(^{*}\right)$.

\section{RESULTS}

The original Amber ff99 does not adequately model the helixes flanking the (5'-GAGU-3') ${ }_{2}$ loop

The original ff99 force field (Cornell et al. 1995; Cheatham et al. 1999) does not include corrections to $\alpha, \gamma$ (Pérez et al. 2007), and glycosidic dihedrals (Zgarbová et al. 2011). It was tested by running two $1-\mu$ sec simulations starting with either the major NMR or an alternative "maximally H-bonded" conformation of the GAGU duplex (Fig. 3). Graphs of 1D and $2 \mathrm{D}$ root-mean-square deviations (RMSD) as a function of time with respect to starting structure of the whole duplex, loop, and helical regions separately are given in Supplemental Figure S1 in the Supplemental Material. Simulations with Amber ff99 are characterized by extensive fraying of the duplex terminal base pairs in both NMR (bulged) and alternative (maximally $\mathrm{H}$-bonded) conformations even though those base pairs are stabilized by a $3^{\prime}$ dangling $A$. In the NMR conformation, the loop remained relatively stable with an RMSD of $\sim 2 \AA$ from the starting structure while the alternative conformation underwent partial unfolding with RMSD rising to about 5 and $6 \AA$ from the starting structure in both simulations. In simulations of both conformations, the formation of "ladder like" conformation occurs, as previously observed when simulating other sequences with ff99 (Banáš et al. 2010; Zgarbová et al. 2011). Thus ff $99+\mathrm{bsc} 0+\mathrm{OL} 3$, which introduced improvements for $\alpha$, $\gamma$, and glycosidic dihedrals, was subsequently tested.

\section{NMR structures of GAGU, GAGC, AAGU, and UAGG duplexes are stable during 1 - $\mu$ sec simulations}

Figure 4 shows the mass-weighted RMSD and average RMSD compared to starting structure for simulations run with Amber ff99 + bsc0 + OL3 (Cornell et al. 1995; Cheatham et al. 1999; Pérez et al. 2007; Zgarbová et al. 2011; Case et al. 2012). Panel (A) gives the RMSD as a function of time while panel (B) gives the average RMSD and the standard deviation as a function of a specific subset of nucleotides in the structure. In addition, the RMSD of structural elements (loop and helical regions) are given in Supplemental Figure S2 in the Supplemental Material. With one exception, the NMR conformation is more stable for all duplexes than the alternative conformation when measured by RMSD to starting structure. The exception is trajectory 3 of the GAGU duplex NMR (bulged) conformation, which has an RMSD similar to GAGU trajectories for the alternative (maximally H-bonded) starting structure. In this trajectory there is transient hydrogen bonding between $\mathrm{A} 5$ and $\mathrm{A} 5^{*}$ nts, which are stacked in the starting conformation, where $\left(^{*}\right)$ refers to opposite strand (Table 1). This is reflected in a higher RMSD of the loop region, but the closing helices remain stable. Figure 4B demonstrates that the main source of instability in all simulations is the loop region, as expected. With one exception, the helical regions have average RMSD to starting structure below $1 \AA$. The exception is trajectory 4 of the GAGU alternative conformation where helix 2 has an average RMSD around $2 \AA$ from the starting structure.

Figure 5 shows histograms of normalized populations of conformations as a function of mass-weighted RMSD to respective starting structures (Fig. 3) calculated over all four runs with Amber ff $99+$ bsc0 + OL3. The presence of single, 

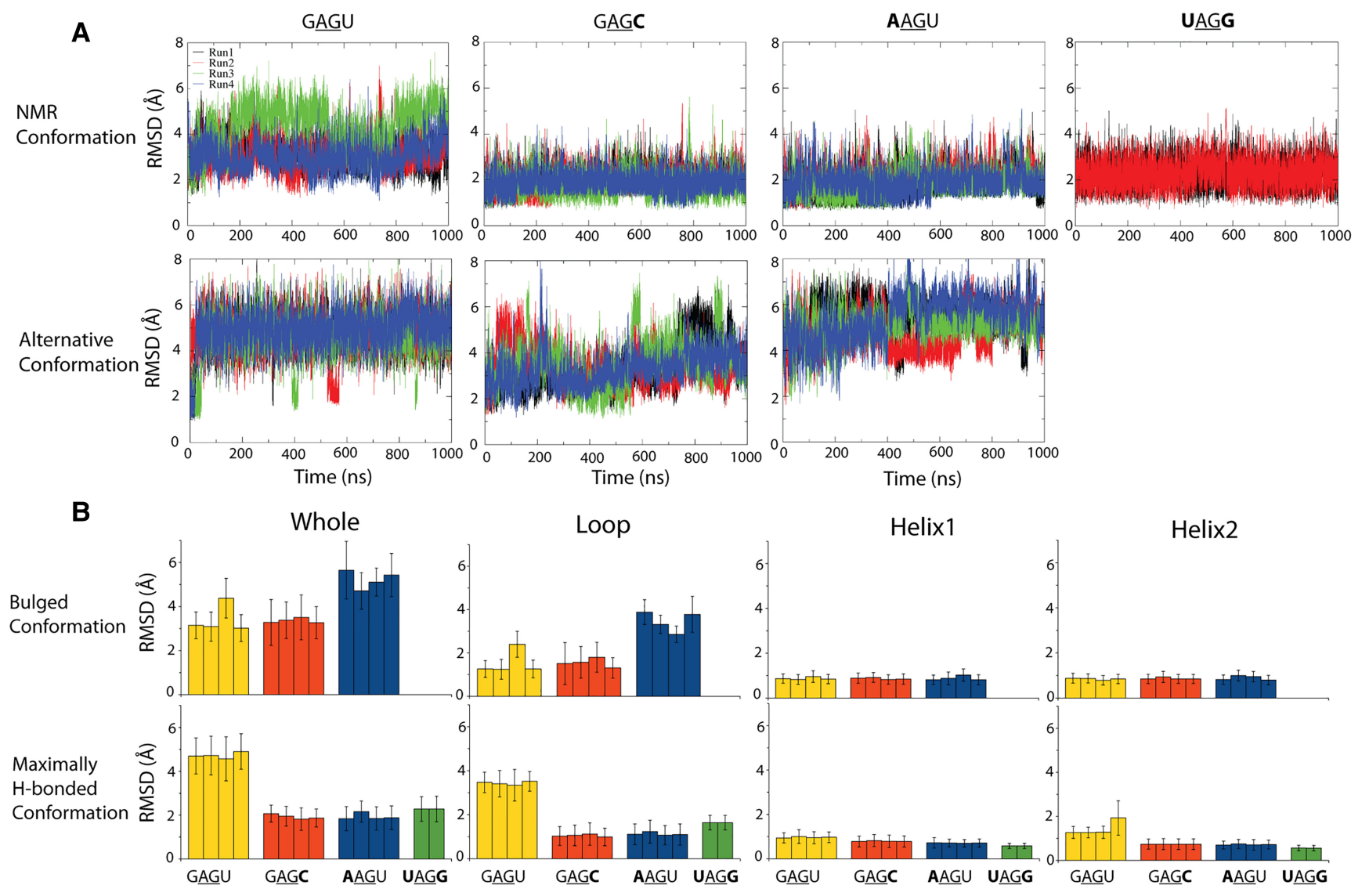

FIGURE 4. (A) RMSD to starting structure of studied duplexes as a function of simulation time with Amber ff99 + bsc0 + OL3. Upper and lower panels show simulations starting with NMR and alternative conformations, respectively. Results for different trajectories are given in different colors. RMSD was mass-weighted and calculated for all atoms. Note the same $y$-axis bounds in all graphs. (B) Average RMSD to starting structure of studied duplexes. Error bars are standard deviations. Upper panel corresponds to the GAGU-like major conformation for all sequences and the lower panel corresponds to the AAGU or GAGC-like, "maximally H-bonded," conformations. Average RMSD is given for the whole molecule, loop region (excluding bulged nucleotides), and the $5^{\prime}$-end and $3^{\prime}$-end helix regions. Note that the $y$-axis bounds are the same in lower and upper panels.

relatively narrow peaks for all duplexes and conformations indicates a homogenous population of conformations across all simulations for a specific duplex and starting conformation. Positions of peaks of populations in simulations starting from NMR conformations are closer to their starting conformation than in simulations starting from alternative conformations. Evidently, the NMR conformations are more stable in the simulations. In GAGU and GAGC duplexes, the peak of population of simulations starting from the NMR structure is about $1 \AA$ lower than the peak of simulations starting from an alternative conformation. In the AAGU duplex this difference is about $3.5 \AA$.

Further information about the ensemble of conformations produced during the simulations was obtained by clustering analysis as described in Materials and Methods. Table 3 shows the Amber ff $99+b s c 0+$ OL3 results of clustering performed on the combined trajectories for all duplexes and starting structures. Similar to the findings in Figure 5, the results indicate a strongly homogeneous population of states with at least $98 \%$ of frames belonging to one cluster in all simulations of duplexes and starting struc- tures. Furthermore, in all but one case, the average distance between elements within a cluster is between 1.6 and $3.2 \AA$. The exception is the alternative (bulged) conformation of the AAGU duplex, which has a broader distribution with an average distance between elements of about $4 \AA$. The centroids of clusters (last column of Table 3) correspond roughly to the peaks of histograms of distribution with respect to mass-weighted RMSD and are shown in Figure 5, where the positions of centroids on the RMSD scale are marked with arrows.

Analysis of 2D RMSD plots of frames in Amber ff99+ $\mathrm{bsc} 0+\mathrm{OL} 3$ trajectories provides more information about the changes in conformation during the simulations. Inspection of 2D RMSD plots (Supplemental Fig. S3 in the Supplemental Material) indicated relative stability of NMR conformations for all sequences. In all but one of the trajectories starting with NMR conformations, a collection of several similar long-lived conformations in each trajectory is separated by no more than 1-2 $\AA$ in RMSD. The exception was simulation 3 of the NMR (bulged) GAGU structure where separation between clusters is between $2-3 \AA$. 

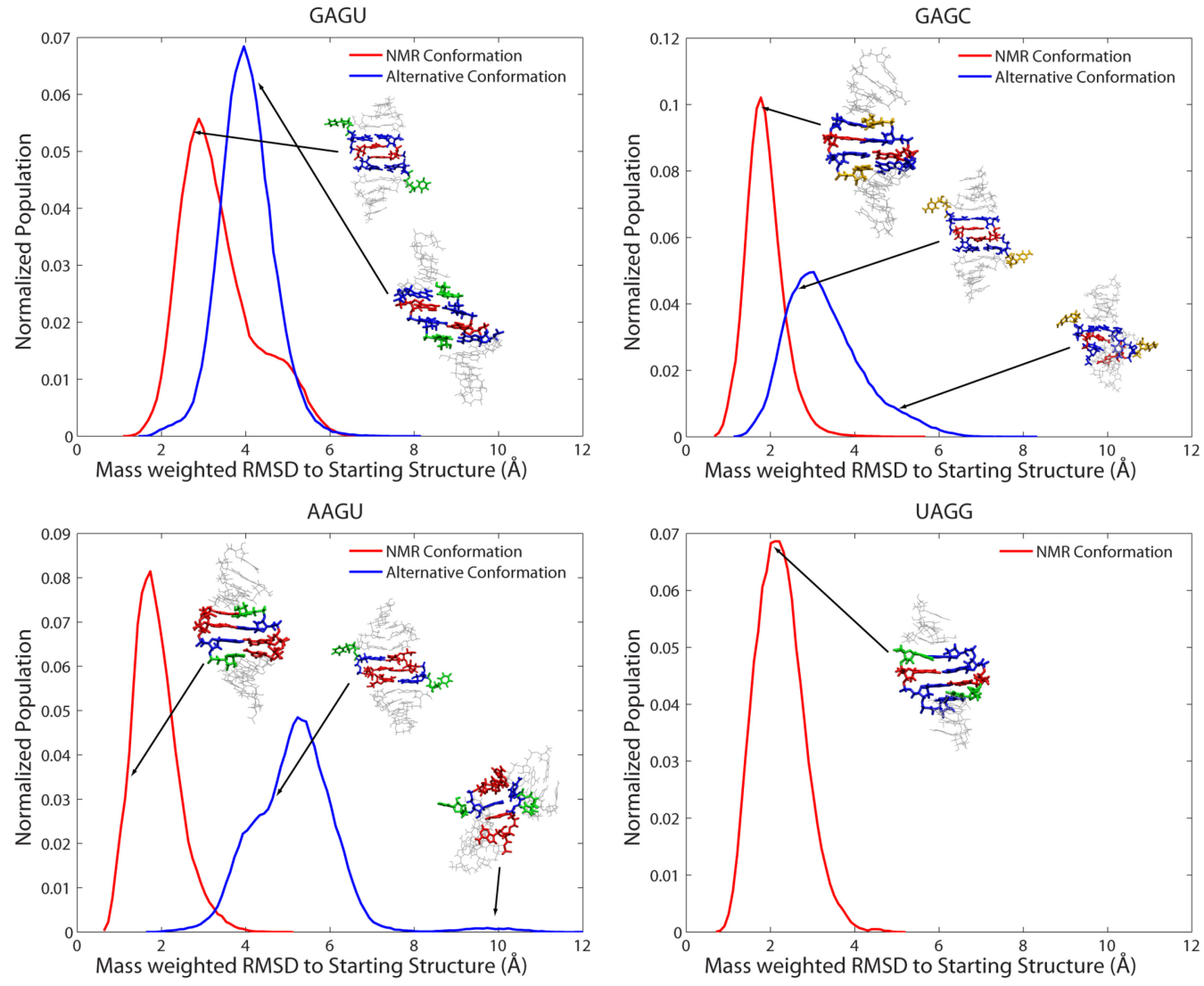

FIGURE 5. Histograms of normalized populations from MD simulations starting with NMR and alternative conformations. Conformations and positions of cluster centroids are indicated. RMSD was mass-weighted to respective starting structure. The results given are the sum of all four (or two for UAGG) Amber ff99 + bsc0 + OL3 runs.

Alternative (bulged) structures for GAGC and AAGU duplexes are less stable than the alternative (maximally $\mathrm{H}$-bonded) structure for the GAGU duplexes

Inspection of 2D RMSD plots of the simulations of the alternative conformations (Fig. 3) indicated a relatively stable
GAGU duplex structure in the alternative (maximally $\mathrm{H}$ bonded) conformation with changes in RMSD generally between 1 and $2 \AA$ along the trajectories. Alternative (bulged) conformations of GAGC and AAGU duplexes are less stable than their NMR (maximally H-bonded) conformations. The

TABLE 3. Clustering results from the combined Amber ff $99+$ bsc $0+$ OL3 trajectories of all four internal loop duplexes run starting from NMR conformation or alternative conformation

\begin{tabular}{|c|c|c|c|c|c|c|c|c|}
\hline Molecule & Conformation & $\begin{array}{c}\% \\
\text { noise }^{a}\end{array}$ & $\begin{array}{c}\text { Cluster } \\
\#\end{array}$ & $\begin{array}{l}\% \text { of } \\
\text { frames }\end{array}$ & $\begin{array}{l}\text { Ave. dist. within } \\
\text { cluster }(\AA)\end{array}$ & $\begin{array}{l}\text { Stdev within } \\
\text { cluster }(\AA)\end{array}$ & $\begin{array}{l}\text { Ave. dist. between } \\
\text { clusters }(\AA)\end{array}$ & $\begin{array}{l}\text { RMSD of centroid to } \\
\text { starting structure }(\AA)\end{array}$ \\
\hline \multirow[t]{2}{*}{ GAGU } & NMR & 0.08 & 1 & 99.9 & 3.18 & 1.05 & 0.0 & 2.74 \\
\hline & Alternative & 0.02 & 1 & 99.8 & 2.39 & 0.70 & 0.0 & 3.79 \\
\hline \multirow[t]{3}{*}{ GAGC } & NMR & 0.05 & 1 & 99.9 & 2.33 & 0.58 & 0.0 & 0.99 \\
\hline & Alternative & 0.5 & 1 & 99.0 & 3.18 & 0.93 & 5.78 & 2.56 \\
\hline & & & 2 & 1.0 & 2.37 & 0.57 & 5.78 & 5.70 \\
\hline \multirow[t]{3}{*}{ AAGU } & NMR & 0.05 & 1 & 99.9 & 2.40 & 0.65 & 0.0 & 0.86 \\
\hline & Alternative & 0.5 & 1 & 98.0 & 4.01 & 1.04 & 8.29 & 4.39 \\
\hline & & & 2 & 1.0 & 2.61 & 0.77 & 8.29 & 9.88 \\
\hline UAGG & NMR & 0.18 & 1 & 99.8 & 1.58 & 0.45 & 0.0 & 1.86 \\
\hline
\end{tabular}

${ }^{\mathrm{a}}$ Noise $\%$ represents frames that do not belong to any cluster.

Starting from the left, columns denote molecule type, starting conformation, \% of noise frames, cluster number, \% of frames within that cluster, average distance and standard deviation between elements of that cluster, average distance between that and all other clusters, and finally mass-weighted RMSD of the centroid of the cluster to the starting conformation of the respective molecule. 
AAGU duplex alternative (bulged) conformation especially had more defined clusters of different structures and a 2-3 $\AA$ change in RMSD along the trajectory (Supplemental Fig. S3 panel C). Transitions between the NMR and alternative conformations, measured by calculating RMSD between frames in trajectories starting with NMR or alternative structure, were not observed for any of the sequences in any of their trajectories (data not shown). This is expected for the GAGU duplex as 2D NOESY, i.e., 2D EXSY (Jeener et al. 1979) NMR experiments indicate a transition time between major and minor conformations on the order of $25 \mathrm{msec}$ at $1^{\circ} \mathrm{C}$ (Supplemental Fig. S4). Thus, the likelihood of a transition within the four $1-\mu \mathrm{sec}$ simulations is low if the force field is accurate.

\section{Amber ff99 + bscO + OL3 largely preserves contacts present} in the NMR structure of the GAGU duplex

Table 4 shows the percentage of NMR determined structural features (as defined in Table 2) that are preserved during the simulations of the NMR (bulged) conformation of the GAGU duplex for all four simulations. The GG trans-WC/ Hoogsteen base pair between G4 and G6* was considered preserved if the distance between all hydrogen bonded atoms (4N7-6*N1, 4O6-6*N2, 4*N7-6N1, and $4 * \mathrm{O} 6-6 \mathrm{~N} 2)$ was between $2.5 \AA$ and $3.5 \AA$. The AA stack was deemed preserved if the distance between 3 pairs of atoms in the stacking adenines $\left(5 \mathrm{AC6}-5^{*} \mathrm{AC} 6,5 \mathrm{AN} 3-5^{*} \mathrm{AN} 3\right.$, and $\left.5 \mathrm{AC} 8-5^{*} \mathrm{AC} 8\right)$ were all within $25 \%$ of their NMR model value $(3.65 \AA, 6.03 \AA$, and $5.10 \AA$, respectively). In the NMR models, the puckers of loop nucleotides (residues $4-7$ and $4^{*}-7^{*}$ ) are centered around $140^{\circ}$ (Kennedy et al. 2012), i.e., close to the lower bound of
$\mathrm{C} 2{ }^{\prime}$-endo conformation. Because of that, $\mathrm{C} 2{ }^{\prime}$-endo conformation was defined as having pucker phase between $120^{\circ}$ and $180^{\circ}$. For the $\mathrm{G}$ residues forming the GG trans-WC/ Hoogsteen base pairs, glycosidic dihedrals with a maximum centered on the syn orientation (between $270^{\circ}$ and $90^{\circ}$ ) were reported in Table 4 as preserved. Only G6 in simulation 3 populated primarily the anti glycosidic dihedral. The G6 sugar pucker, however, never visits the C3'-endo conformation and the G6-G15 hydrogen bonding remains trans-WC/ Hoogsteen throughout the simulation. For all types of NMR contacts, the average value of all measured quantities was reported for each simulation independently. The results indicate that the NMR contacts are well preserved with typical averages of over $90 \%$ preserved distance-related NMR contacts. The only exception was simulation 3 , where only $34.8 \%$ of the frames have the stacking between A residues and $81.9 \%$ of frames have the GG pairs. NMR-detected $\mathrm{C} 2$ '-endo sugar puckers were also well preserved, with the exception of all G6/G6* puckers and G4 pucker in simulation 3, which were primarily $\mathrm{C}^{\prime}$-endo. Carbon- 13 chemical shifts of $\mathrm{G6} / \mathrm{G6}^{*} \mathrm{C1}^{\prime}$ atoms are downfield from other $\mathrm{Cl}^{\prime}$ atoms in the loop and may indicate less preference of that residue for the C2'-endo sugar pucker (Supplemental Table S2).

In addition to the contacts described above, the NMR (bulged) model of the GAGU duplex contains H-bonds between the amino group of A5 and $\mathrm{O} 2^{\prime}$ atoms from $\mathrm{G} 4{ }^{*}$ and $A 5^{*}$ on the opposite strand and the equivalent interactions between A5* and G4 and A5 (Fig. 6). Table 4 lists the percentage of these interactions that are preserved in all four simulations starting with the NMR (bulged) conformation of the GAGU sequence. The H-bonds were deemed present if the distance between the corresponding heavy atoms was $<4 \AA$.

TABLE 4. Percentage of NMR contacts preserved during simulations starting with the NMR conformation of $\left(5^{\prime}-\mathrm{GAGU}-3^{\prime}\right)_{2}$ duplex

\begin{tabular}{|c|c|c|c|c|}
\hline \multirow[b]{2}{*}{ Type of NMR contact } & \multicolumn{4}{|c|}{ Value } \\
\hline & Sim. 1 & Sim. 2 & Sim. 3 & Sim. 4 \\
\hline GG trans-WC/Hoogsteen base pair & 90.1 & 92.2 & 81.9 & 92.5 \\
\hline AA stack & 95.4 & 92.8 & 34.8 & 94.5 \\
\hline \multirow[t]{8}{*}{$2^{\prime}$-endo pucker loop nucleotides (4-7 and 15-18) } & G4: 71.8 & G4: 85.2 & G4: 12.4 & G4: 87.6 \\
\hline & A5: 67.5 & A5: 81.3 & A5: 63.1 & A5: 82.4 \\
\hline & G6: 16.8 & G6: 8.3 & G6: 38.8 & G6: 6.2 \\
\hline & U7: 69.7 & U7: 70.8 & U7: 95.3 & U7: 67.8 \\
\hline & G4*: 67.1 & G4*: 80.7 & G4*: 57.5 & G4*: 68.6 \\
\hline & $\mathrm{A} 5^{*}: 71.8$ & $\mathrm{~A} 5^{*}: 74.8$ & $\mathrm{~A} 5^{*}: 46.2$ & A5*: 69.1 \\
\hline & G6*: 4.2 & G6*: 24.3 & G6*: 0.4 & G6*: 18.5 \\
\hline & U7*: 66.5 & $U 7^{*}: 74.6$ & U7*: 67.5 & U7*: 80.2 \\
\hline \multirow{4}{*}{ Syn glycosidic dihedrals on G4/G4* and G6/G6* } & G4: 100 & G4: 100 & G4: 100 & G4: 100 \\
\hline & G6: 83.9 & G6: 90.9 & G6: 14.9 & G6: 88.6 \\
\hline & G4*: 100 & $\mathrm{G} 4 *: 100$ & G4*: 100 & G4*: 100 \\
\hline & G6*: 94.6 & G6*: 69.7 & G6*: 100 & G6*: 75.7 \\
\hline 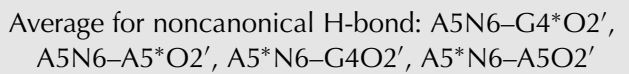 & 76.2 & 81.6 & 36.3 & 79.0 \\
\hline
\end{tabular}

The results from different simulations are in different columns. All results are presented as a percentage of interactions present in the NMR structure that were preserved during the simulation. A hydrogen bond was considered formed if the distance between $\mathrm{H}$ and acceptor atom was $<4 \AA$. For more details on how NMR contacts were defined, see Results section. 


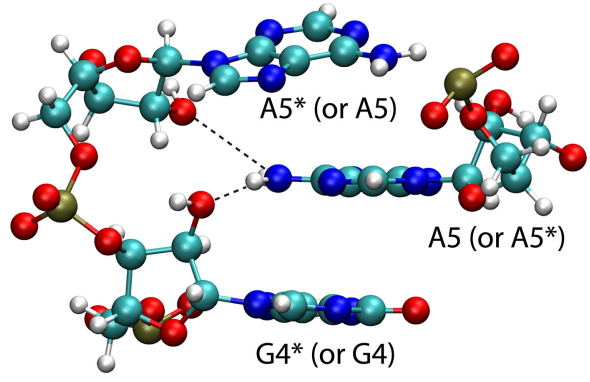

FIGURE 6. Two stabilizing interactions in the $\left(5^{\prime}-\mathrm{GAGU}-3^{\prime}\right)_{2} \mathrm{NMR}$ major structure. Hydrogen bonding between A5 amino group and $2^{\prime}-$ oxygen on $\mathrm{G}^{*}$ and $\mathrm{A} 5^{*}$ residues on the complementary strand.

As Table 4 shows, the stabilizing $\mathrm{H}$-bonds are preserved in over $75 \%$ of the frames in all but simulation 3 where it was only about $36 \%$.

NMR spectra for a construct with the amino group of A5 replaced by a hydrogen reveal that the $\mathrm{H}$-bonds involving that amino group are not essential for formation of the GAGU NMR (bulged) structure

As described above, both NMR and MD simulations of the GAGU duplex contain H-bonds between the amino group of A5 and cross-strand $\mathrm{O}^{\prime}$ atoms (Fig. 6). To test if these interactions are essential for formation of the GAGU NMR (bulged) structure, A5 was replaced by purine to substitute hydrogen for the amino group of A5. Based on 1D spectra (Supplemental Fig. S5A,B), purine substitution apparently causes the stability of the duplex to decrease relative to hairpin. However, 2D spectra of the modified and unmodified duplexes are similar (Supplemental Fig. S5C), indicating that the structures of the duplexes are essentially the same. In particular, NOEs G6H1-G4*H8, G6H8- ${ }^{\prime} 1^{\prime}$, and G4H8$\mathrm{H}^{\prime}$, and others are found in both spectra. Moreover, there is a new NOE from the purine $\mathrm{H} 6$ to the cross-strand $\mathrm{G} 4^{*} \mathrm{H} 2^{\prime}$, which places the purine $\mathrm{H} 6$ at the spatial position of the A5 amino group in the 3D model of the unmodified duplex. Evidently, the A5 amino group is positioned to allow $\mathrm{H}$-bonding to cross-strand $2^{\prime} \mathrm{OH}$ groups, but these $\mathrm{H}$-bonds are not essential for stabilizing the GAGU NMR (bulged) structure.

MD simulations starting with the maximally $\mathrm{H}$-bonded alternative conformation for the $\left(5^{\prime}-G A G U-3^{\prime}\right)_{2}$ internal loop suggest an unusual minor conformation

NMR experiments indicate that a minor conformation is present for the GAGU duplex, but no detailed structure has been proposed other than to note that G4/4* and G6/6* residues are in the ant $i$ conformation and that $\mathrm{U} 7 / 7^{*}$ residues are stacked instead of bulged out (Hammond et al. 2010). Because the maximally $\mathrm{H}$-bonded alternative conformation in Figure 3 is a plausible minor conformation, MD simulations starting with this structure were run. Figures 4 and 5 and Table 3 indicate that the alternative conformation of the $\left(5^{\prime} \text {-GAGU-3' }\right)_{2}$ internal loop maintains an essentially single conformation during all four simulations at around $4 \AA$ distance from the maximally $\mathrm{H}$-bonded starting structure. The centroid structure of the single cluster produced from clustering all trajectories starting with the alternative (maximally H-bonded) conformation of the GAGU duplex is given in Figure 7. In this structure, helices remain relatively stable with only about $1 \AA$ RMSD distance from the starting conformation, but the loop region undergoes significant reorganization resulting in about $4.5 \AA$ RMSD difference from the starting structure. The closing GU pairs are changed from GU wobble to GU cis-Watson-Crick/sugar edge type (Leontis et al. 2002) where O2 from uracil forms a shared $\mathrm{H}$-bond with both amino and imino groups from guanine and the amino group of $\mathrm{G} 4$ also forms a H-bond with $\mathrm{O}^{\prime}$ from ribose (Fig. 7C). These $\mathrm{H}$-bonds are preserved throughout all four simulations. The average and standard deviations for $4 \mathrm{O} 6-7^{*} \mathrm{~N} 3,4 \mathrm{~N} 1-7^{*} \mathrm{O} 2$, and $4 \mathrm{~N} 2-7^{*} \mathrm{O} 2^{\prime}$ bonds between G4 and $\mathrm{U}^{*}$ are $3.1 \pm 0.4 \AA, 3.0 \pm 0.3 \AA$, and $3.9 \pm 0.7 \AA$; and for the $7 \mathrm{~N} 3-4^{*} \mathrm{O} 6,7 \mathrm{O} 2-4^{*} \mathrm{~N} 1$, and $7 \mathrm{O} 2^{\prime}-4^{*} \mathrm{~N} 2$ bonds between $\mathrm{U} 7$ and $\mathrm{G} 4^{*}$, the values are $3.1 \pm 0.5 \AA, 3.0 \pm 0.3 \AA$, and $3.9 \pm 0.8 \AA$.

AG imino $\mathrm{H}$-bonds from the initial GAGU maximally $\mathrm{H}-$ bonded starting structure are changed as well, with only a single $\mathrm{H}$-bond between $\mathrm{N} 1$ of adenine and the amino group of guanine. These $\mathrm{H}$-bonds remain throughout all simulations with an average distance and standard deviations of $3.1 \pm$ $0.3 \AA$ for the bonds in A5-G6* and G6-A5* base pairs. The stacking between G4-U7* and A5-G6* base pairs is reduced as well (Fig. 7B). According to the clustering procedure in Table 3, the centroid conformation is stable. It encompasses $99.8 \%$ of all frames in all trajectories with standard deviation between them of only $0.7 \AA$. The sequence does visit the starting maximally $\mathrm{H}$-bonded conformation as can be seen from the transient excursions to RMSD of around $2 \AA$ in Figure 4, although this behavior is not captured in a separate cluster by the clustering procedure. Thus, trajectories starting with the alternative (maximally H-bonded) conformation, of the GAGU duplex provide models for minor conformations. We call the MD-generated internal loop structure a G4\&G6 $\mathrm{NH}_{2} \mathrm{H}$-bonded conformation.

NMR spectra are consistent with the G4\&G6 $\mathrm{NH}_{2} \mathrm{H}$-bonded minor conformation of $\left(5^{\prime}-G A G U-3^{\prime}\right)_{2}$ generated

by $M D$ simulations

Multiple lines of NMR evidence suggest that the G4\&G6 $\mathrm{NH}_{2}$ $\mathrm{H}$-bonded conformation modeled by $\mathrm{MD}$ and represented in Figure 7 (left column) is a more accurate representation of the minor conformation of the $\left(5^{\prime}-\mathrm{GAGU}-3^{\prime}\right)_{2}$ internal loop than is the maximally $\mathrm{H}$-bonded starting structure. Minor conformation resonances for $\mathrm{H} 1, \mathrm{H} 3, \mathrm{H} 2, \mathrm{H} 8, \mathrm{H} 6$, and $\mathrm{H}^{\prime}$ atoms are assigned through intense exchange cross-peaks to major conformation resonances and are listed 
A
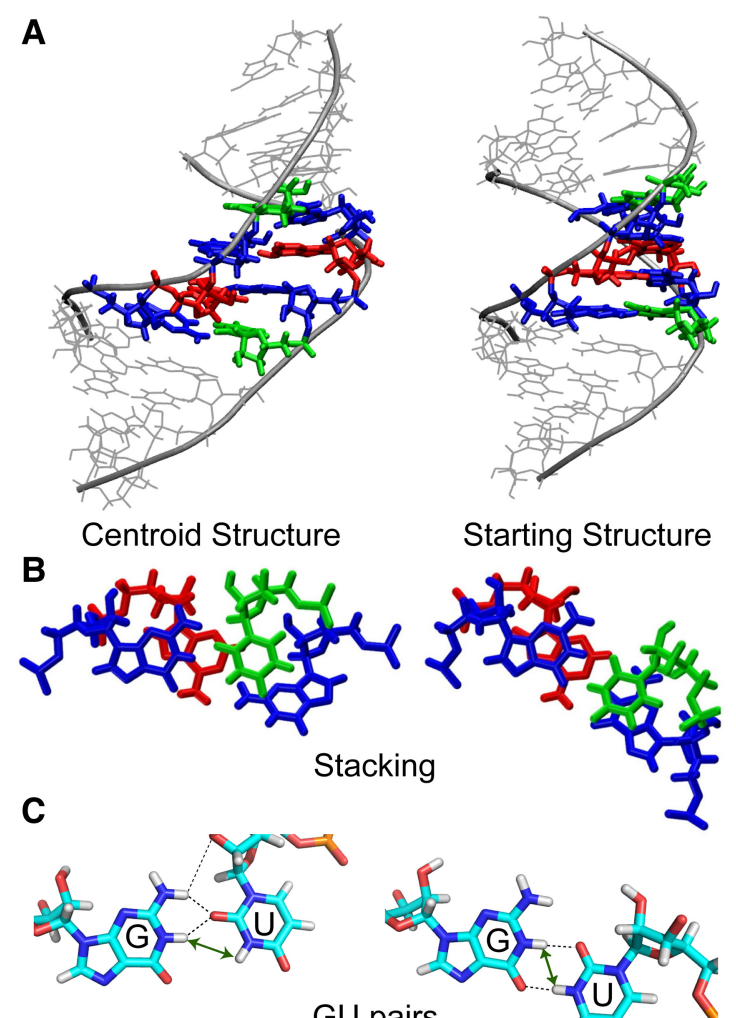

D

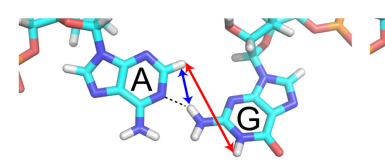

AG pairs
Starting Structure
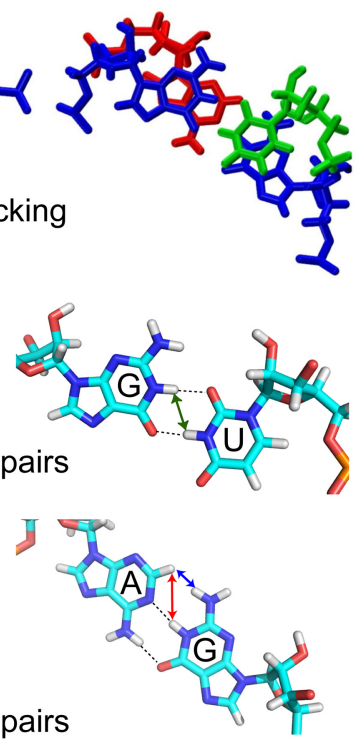

FIGURE 7. (Left column) Structure of the centroid of the only cluster from the simulations of the alternative (maximally H-bonded) conformation of GAGU duplex. (Right column) Starting structure of the GAGU (maximally H-bonded) alternative simulations. We call the centroid structure G4\&G6 $\mathrm{NH}_{2} \mathrm{H}$-bonded conformation. Panel $A$ shows the overall structures emphasizing the difference in the minor grooves. Panel $B$ shows the difference in stacking. Panels $C$ and $D$ show the hydrogen bonding (dashed lines) in the $(C)$ GU pairs and (D) AG pairs. Blue, red, and green arrows in the AG and GU pairs correspond to NOESY cross-peaks (or lack of them) indicated with circles of corresponding color in Figures 8, 10A, 11, and Supplemental Figure S6.

in Supplemental Table S1. As previously observed (Hammond et al. 2010), the upfield shift of U7H5 and U7H6 in the minor conformation relative to their values in the major conformation suggest that U7 is stacked in the helix. Drastically reduced $\mathrm{H}^{\prime}-\mathrm{H} 8$ NOESY cross-peaks for G4 and G6 indicate these bases are in the anti conformation (Hammond et al. 2010). In addition, none of the minor-conformation $\mathrm{H}^{\prime}$ resonances exhibit scalar-coupling to $\mathrm{H}^{\prime}$ resonances greater than $2 \mathrm{~Hz}$, indicating that all sugar residues are primarily in the $\mathrm{C}^{\prime}$-endo conformation (Hammond et al. 2010). However, the observations that sugar residues are all $\mathrm{C}^{\prime}$-endo, all bases are in the anti conformation, and

U7 is stacked in the helix, do not distinguish between the G4\&G6 $\mathrm{NH}_{2} \mathrm{H}$-bonded and maximally H-bonded starting structure.

Figure 8 shows a 2D NOESY spectrum of the non-selfcomplementary duplex 5'GACGAGUGAGA/3'ACUGUG AGCUC. This sequence was used to solve the structure of the major GAGU duplex conformation (Kennedy et al. 2012). A NOESY cross-peak between G6m amino protons and $\mathrm{A}^{*} \mathrm{mH} 2$ in the minor $(\mathrm{m})$ conformation (Fig. 8, blue circle) could indicate an AG imino pair (Fig. 7D, right). This cross-peak, however, is also consistent with the G6 $\mathrm{NH}_{2} \mathrm{H}$-bonded AG pair observed in the MD simulation (Fig. 7D, left). In an AG imino pair, the GH22-AH2 distance is $\sim 2.0-2.2 \AA$, while in the $\mathrm{G} 6 \mathrm{NH}_{2} \mathrm{H}$-bonded AG pair the GH21-AH2 distance is $\sim 2.6-2.8 \AA$. On the other hand, no NOESY cross-peak is observed between G6mH1 and A5* $\mathrm{mH} 2$ (Fig. 8, red circle). This peak is typically observed in AG imino pairs (Peterson et al. 1994; Wu and Turner 1996; Hammond et al. 2010), but should be much weaker or missing in the $\mathrm{G} 6 \mathrm{NH}_{2} \mathrm{H}$-bonded AG pair (Fig. 7D, left). Consequently, the NOESY pattern is most consistent with the $\mathrm{G} 6 \mathrm{NH}_{2} \mathrm{H}$-bonded AG pair, unless the missing G6mH1-A5* $\mathrm{mH} 2$ cross-peak is a consequence of imino proton water exchange. Water exchange is likely ruled out, however, because there is a reasonably sized G6mH1$\mathrm{G} 6 \mathrm{mNH}_{2}$ peak and at least one other cross-peak to G6mH1 (Fig. 8; black arrow). By process of elimination, this peak can only be from G6mH1 to $\mathrm{A} 5^{*}$ amino or a $2^{\prime} \mathrm{OH}$. In either an $\mathrm{AG}$ imino pair or a $\mathrm{G} 6 \mathrm{NH}_{2} \mathrm{H}$-bonded pair, the NOE from $\mathrm{G} 6 \mathrm{H} 1$ to an $\mathrm{A5}^{*}$ amino or a $2^{\prime} \mathrm{OH}$ (both of which are exchangeable protons) will be substantially weaker than to the nonexchangeable $\mathrm{A} 5^{*} \mathrm{H} 2$ in an AG imino pair. Thus, water exchange cannot explain the absence of a G6mH1-A5* $\mathrm{mH} 2$ cross-peak if it were an AG imino pair. Distances between protons in Figure 7D, however, show that a G6mH1-A5* $\mathrm{mNH}_{2}$ cross-peak is consistent with spin diffusion through $\mathrm{G} 6 \mathrm{mNH}_{2}$ in a G6 $\mathrm{NH}_{2} \mathrm{H}-$ bonded AG pair.

In a canonical AG imino pair (Fig. 2), the GH1 proton is involved in a $\mathrm{H}$-bond to AN1, resulting in GH1 chemical shifts typically greater than $12 \mathrm{ppm}$ (Peterson et al. 1994; $\mathrm{Wu}$ and Turner 1996; Wu et al. 1997; Hammond et al. 2010; Chen et al. 2015). An exception is the loop (5'UAGA- $\left.3^{\prime}\right)_{2}$, where GH1 is stacked between two six-membered purine rings which cause an upfield shift to 11.6 ppm (Hammond et al. 2010). The signal for G6mH1 (minor conformation) of $\left(5^{\prime} \text {-GAGU- } 3^{\prime}\right)_{2}$ is relatively upfield at 10.9 $\mathrm{ppm}$ in the spectrum of the non-self-complementary duplex (Fig. 8). This region is typically associated with $\mathrm{G}$ imino protons $\mathrm{H}$-bonded to carbonyl oxygen atoms, or not hydrogen bonded at all. It would be an unusual shift for a H-bond to nitrogen. This upfield shift might be consistent with the G6 $\mathrm{NH}_{2} \mathrm{H}$-bonded AG pair where $\mathrm{GH} 1$ is not involved in a $\mathrm{H}$-bond, or perhaps a rapidly exchanging mixture of imino and $\mathrm{G} 6 \mathrm{NH}_{2} \mathrm{H}$-bonded AG pairs. 


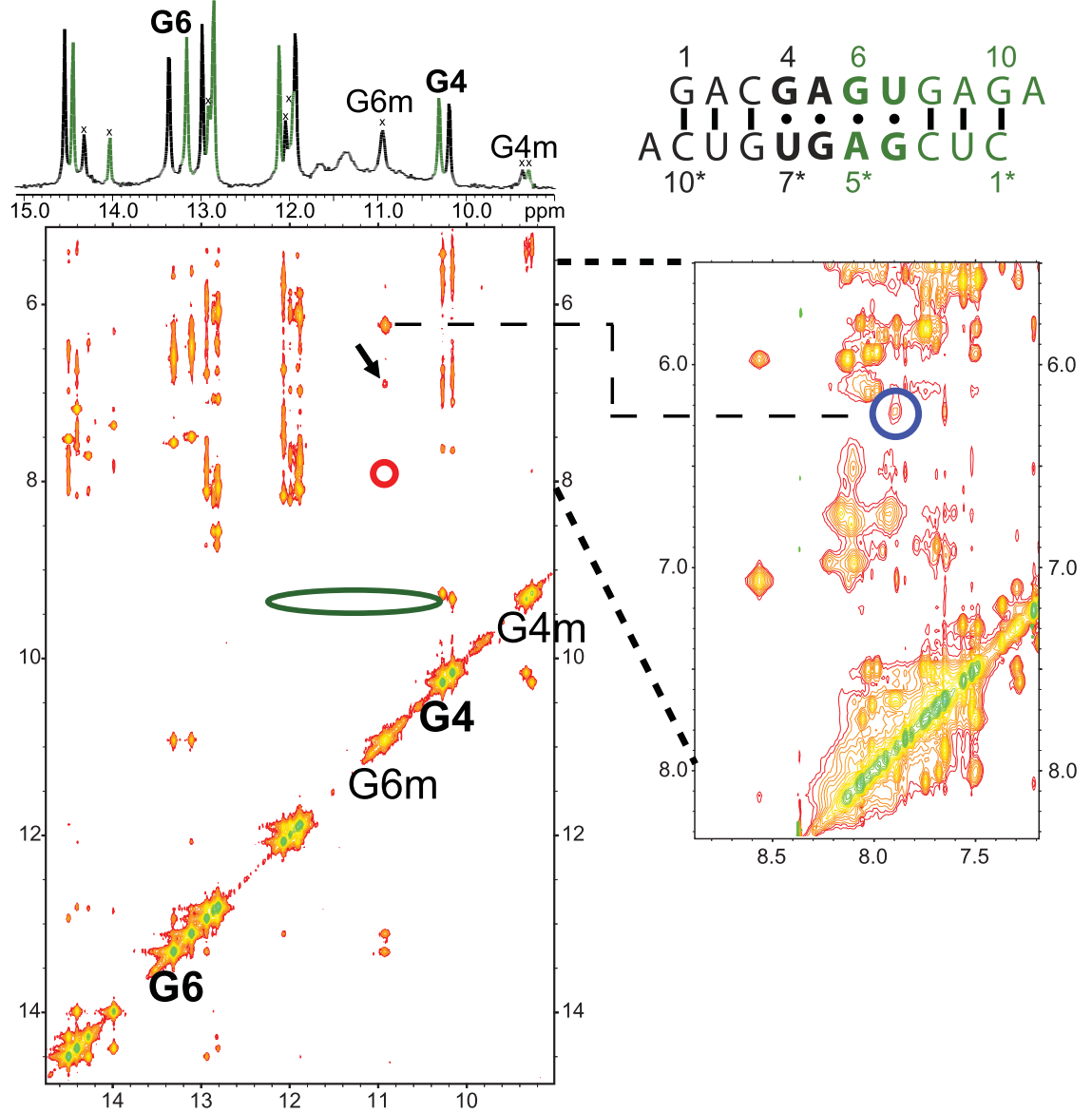

FIGURE 8. 2D NOESY spectrum (mixing time $50 \mathrm{msec} ;-3^{\circ} \mathrm{C} ; 0.9 \mathrm{mM}$ strands) of non-selfcomplementary duplex, 5'GACGAGUGAGA/3'ACUGUGAGCUC. G6 and G4 H1 (imino) signals of both strands are labeled on the diagonal and on the $1 \mathrm{D}$ spectrum (top); " $\mathrm{m}$ " refers to the minor conformation. The strong cross-peak from G6m imino at $11 \mathrm{ppm}$ to $6.25 \mathrm{ppm}$ is due to G6m amino protons ( $\mathrm{H} 21$ and $\mathrm{H} 22$ ), which also have a cross-peak (blue circle) to A5 ${ }^{*} \mathrm{H} 2$. The red circle highlights the lack of a cross-peak between G6m imino and A5* $\mathrm{H} 2$ that is typically observed in an AG imino pair. The green ellipse at G4m $(9.4 \mathrm{ppm})$ indicates the lack of cross-peaks to U7H3 as might be observed in a GU wobble pair. The black arrow indicates an unassigned cross-peak to G6m H1. NOESY cross-peaks (or lack of them) indicated by blue, red, and green circles correspond to interproton distances indicated by colored arrows in Figure $7 \mathrm{C}$ and $\mathrm{D}$.

No evidence of any G4mH1-U7*mH3 (or G4*mH1$\mathrm{U} 7 \mathrm{mH} 3$ ) cross-peak is found in 2D NOESY spectra of unmodified GAGU duplex. This strong peak is expected if a GU wobble pair was formed in minor conformations (Fig. 8; green oval at $\mathrm{G} 4 \mathrm{mH} 1$ ). However, this is not surprising as $\mathrm{U} 7 \mathrm{H} 3$ peaks are very broad or not observed in the $1 \mathrm{D}$ spectrum, perhaps due to rapid water exchange or dynamics. Rapid exchange of U7H3 with water is more consistent with a $\mathrm{G} 4 \mathrm{NH}_{2} \mathrm{H}$-bonded GU pair where $\mathrm{U} 7 \mathrm{H} 3$ would be solvent exposed in contrast to a GU wobble pair where $\mathrm{U} 7 \mathrm{H} 3$ would be protected by a H-bond.

In order to further characterize the minor conformation, including the MD-modeled unusual GU and AG pairs, structural properties of constructs containing chemically modified nucleotides were investigated. These include guanosine to inosine modifications which examine the significance of $\mathrm{G}$ amino group interactions, and sugar modifications which stabilize the $\mathrm{C}^{\prime}$-endo conformation observed in the minor conformation.

\section{Guanosine to inosine substitutions}

The NMR model of the major (bulged) conformation of the $\left(5^{\prime}-\mathrm{GAGU}-3^{\prime}\right)_{2}$ internal loop has a $\mathrm{H}$-bond between the amino group of G4 and an intranucleotide nonbridging phosphate oxygen. There is also an amino proton of $\mathrm{G} 6 \mathrm{H}$ bonded to the carbonyl oxygen of $\mathrm{G} 4$ * on the other strand (Fig. 2D). The minor (G4\&G6 $\mathrm{NH}_{2} \mathrm{H}$-bonded) conformation generated by $\mathrm{MD}$ simulations (Fig. 7, left) has interstrand $\mathrm{H}$-bonds formed by the amino groups of both G4 and G6. In contrast, no internucleotide hydrogen bonding is expected for the amino protons of $\mathrm{G}$ in $\mathrm{GU}$ wobble and $\mathrm{AG}$ imino pairs (Fig. 7C,D, right). Inosine (I) differs from guanosine in that the guanosine $\mathrm{NH}_{2}$ group is replaced by a hydrogen. Thus, if either G4 or G6 is replaced by inosine, the $\left(5^{\prime}-\mathrm{GAGU}-3^{\prime}\right)_{2}$ internal loop NMR major (bulged) and minor (G4\&G6 NH $\mathrm{NH}_{2} \mathrm{H}$-bonded) conformations are expected to be destabilized while a minor conformation consisting of $\mathrm{GU}$ wobble and AG imino pairs would be relatively unaffected. NMR spectra (Fig. 9B, C) for rGACIAGUGUCA (4I) and rGACGAIUGUCA (6I) indicate that the $\left(5^{\prime}-\mathrm{GAGU}-3^{\prime}\right)_{2}$ major (bulged) conformation is not formed by either $4 \mathrm{I}$ or $6 \mathrm{I}$. The 6 I sequence forms a duplex with IA imino and GU wobble pairs as indicated by NOE cross-peaks (Fig. 10A) and a population of a hairpin conformation as indicated by the concentration dependence of resonance areas (Fig. 10B). In contrast, spectra of $4 \mathrm{I}$ do not suggest formation of AG imino or IU wobble pairs. Rather, the 4I spectra indicate formation of a hairpin conformation despite a slightly higher RNA concentration than for the 6I sample. The hairpin conformation is consistent with lack of imino proton spectral changes in response to 50 -fold dilution of the sample (Fig. 9B). Evidently, the amino group of G4 is required for formation of a duplex. The bifurcated $\mathrm{GU} \mathrm{H}$ bond in the $\mathrm{G} 4 \mathrm{NH}_{2} \mathrm{H}$-bonded conformation of MD simulations (Fig. 7) that were started with the $\left(5^{\prime}-\mathrm{GAGU}-3^{\prime}\right)_{2}$ maximally $\mathrm{H}$-bonded conformation is consistent with involvement of the G4 amino, but a wobble conformation is not. Also, the bifurcated H-bond is consistent with lack of 


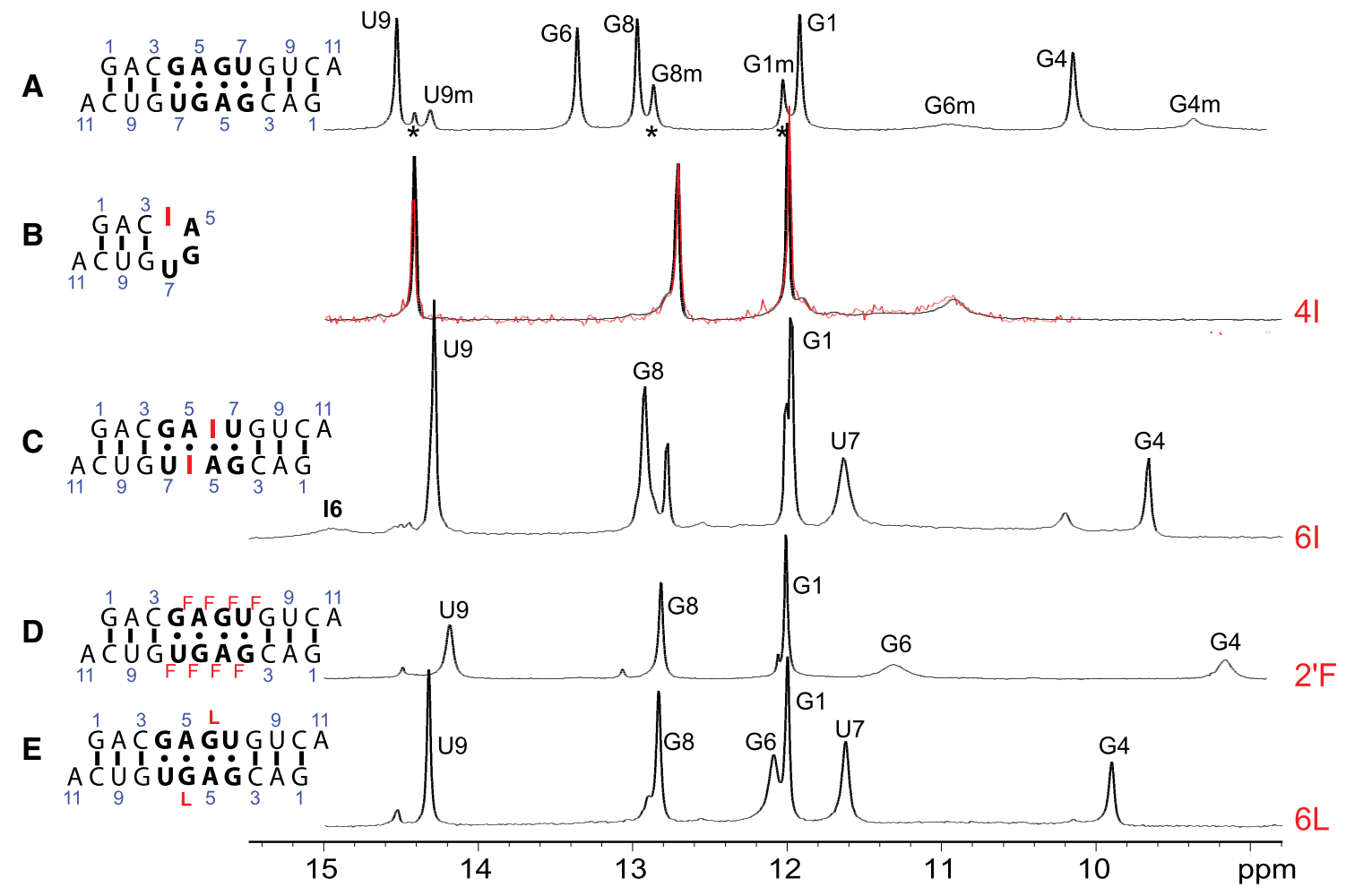

FIGURE 9. NMR spectra of the imino region of $(A)$ unmodified self-complementary duplex, $\left(5^{\prime} \text { GACGAGUGUCA }\right)_{2},(2.0 \mathrm{mM}$ strands) (Hammond et al. 2010); (B) guanosine to inosine substitution at position 4 (4I); black and red indicate $1.2 \mathrm{mM}$ and $24 \mu \mathrm{M}$ RNA strands, respectively; (C) guanosine to inosine substitution at position 6 (6I) (1.1 mM strands); (D) 2'OH to $2^{\prime} \mathrm{F}$ substitution at positions 4-7 (2F) (2.4 mM strands); and (E) guanosine to $\mathrm{G}$ locked nucleic acid (LNA) substitution at position $6(6 \mathrm{~L})$ (1.3 $\mathrm{mM}$ strands). Asterisks identify peaks from hairpin conformation. All spectra at $1^{\circ} \mathrm{C}$ except $(C)$ which is at $-2^{\circ} \mathrm{C}$.

a U7H3 resonance as this proton is exposed to solvent without protection by a H-bond. In contrast, a wobble GU pair would generate a U7H3 resonance (Johnston and Redfield 1981). Thus, the NMR spectra for 4I are consistent with the MD prediction of an unexpected G4\&G6 $\mathrm{NH}_{2} \mathrm{H}$-bonded minor structure for the GAGU duplex.

It is somewhat surprising that the $4 \mathrm{I}$ sequence forms a hairpin with no indication of a duplex. IU pairs are known to form (Pan et al. 1998) and at the NMR temperature of $1^{\circ}$ $\mathrm{C}$, the free energy increment for the $5^{\prime} \mathrm{CI} / 3^{\prime} \mathrm{GU}$ nearest neighbor in a potential duplex is $-2.1 \mathrm{kcal} / \mathrm{mol}$ (Wright et al. 2007), which is more favorable than the $-1.7 \mathrm{kcal} /$ mol for a $5^{\prime} \mathrm{CG} / 3^{\prime} \mathrm{GU}$ nearest neighbor (Chen et al. 2012). The relative stabilities of $5^{\prime} \mathrm{GA} / 3^{\prime} \mathrm{UG}$ and $5^{\prime} \mathrm{IA} / 3^{\prime} \mathrm{UG}$ nearest neighbors, however, are unknown. Moreover, the hairpin structure may be stabilized by the presence of a $3^{\prime}$ dangling $\mathrm{I}$ in the loop. At $1^{\circ} \mathrm{C}$, that would provide a favorable increment of $-2.8 \mathrm{kcal} / \mathrm{mol}$ (Turner et al. 1987). This interaction may explain the dominant hairpin structure of $4 \mathrm{I}$. That is, the flexibility of inosine as a $3^{\prime}$ dangling end at the beginning of a hairpin loop may provide a more favorable free energy than a constrained IU pair with a CG pair on one side and unfavorable stacking on an AG pair on the other side.
Chemical modifications that restrain the sugar conformation to $\mathrm{C} 3^{\prime}$-endo

Replacement of loop residues with nucleotides having "locked" (LNA) (Vester and Wengel 2004) or $2^{\prime} \mathrm{F}$ sugars (Manoharan et al. 2011) to favor $\mathrm{C}^{\prime}$ - endo sugar pucker largely eliminates the major NMR (bulged) conformation of the GAGU duplex, where all loop residues are $\mathrm{C} 2^{\prime}$-endo. The resulting conformations are more similar to all-Watson-Crick duplexes (Figs. 9D,E, 11; Supplemental Fig. S6). When G6 is replaced with LNA-G, a GH1-UH3 cross-peak indicative of a GU wobble pair is found in 2D NOESY spectra (Supplemental Fig. S6), although U7H3 is rapidly exchanging with solvent (note the weak U7H3 diagonal-peak in 2D NOESY spectrum of duplex 6L). Also, the LNA-G6H1 resonance is farther downfield at $12.1 \mathrm{ppm}$ than in the minor structure of the unmodified GAGU duplex or in the $2^{\prime} \mathrm{F}$ duplex (Fig. 9D,E; Supplemental Table S1). Moreover, a weak cross-peak from LNAG6H1 to ${ }^{*}{ }^{*} \mathrm{H} 2$ is observed in a 2D NOESY spectrum of duplex 6L (Supplemental Fig. S6). Thus, duplex 6L appears to have a significant population of the maximally $\mathrm{H}$-bonded AG imino/GU wobble conformation.

The 2D NOESY spectra of duplex $2^{\prime} \mathrm{F}$ show a strong crosspeak between G6 amino and a peak identified by process of 

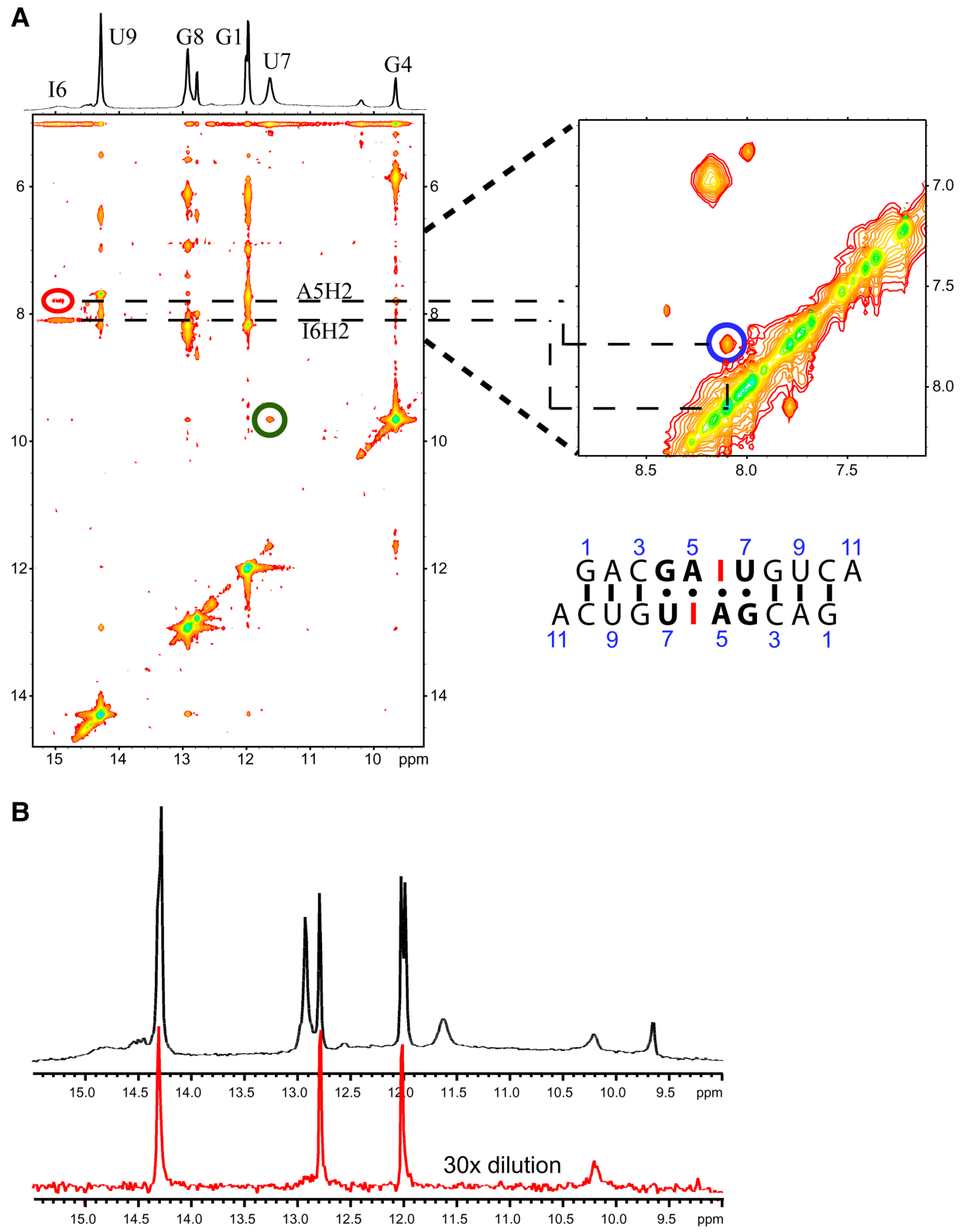

FIGURE 10. (A) 2D NOESY and $1 \mathrm{D}$ spectrum of $\mathrm{r}(\mathrm{GACGAIUGUCA})_{2}(6 \mathrm{I})$ at $1.1 \mathrm{mM}$ strand. Temperature is $-2^{\circ} \mathrm{C}$ with $50 \mathrm{msec}$ mixing time. Blue, red, and green circles correspond to NOESY cross-peaks between protons indicated by colored arrows in Figure 7C and D. $(B)$ Imino proton spectrum at $1^{\circ} \mathrm{C}$ of $6 \mathrm{I}$ at $1.1 \mathrm{mM}$ strand (top) and diluted 30-fold (bottom, 15-fold vertical expansion). Peaks remaining at low concentration belong to a hairpin conformation.

elimination as A5 amino (Fig. 11, black arrow). This crosspeak is expected in the $\mathrm{G} 4 \& \mathrm{G} 6 \mathrm{NH}_{2} \mathrm{H}$-bonded conformation, but should be missing or weak in the maximally H-bonded starting conformation (Fig. 7). Further, the U7H3 signal is missing, as would be expected for the solvent-exposed U7H3 of the G4\&G6 $\mathrm{NH}_{2}$ H-bonded conformation. Evidently, duplex $2^{\prime} \mathrm{F}$ primarily exhibits the $\mathrm{G} 4 \& \mathrm{G} 6 \mathrm{NH}_{2} \mathrm{H}-$ bonded conformation of Figure 7. Based on NOE and chemical shift patterns, duplex $2^{\prime} \mathrm{F}$ appears most similar to the unmodified, minor conformation (Figs. 9D, 11; Supplemental Table S1).

\section{DISCUSSION}

There is a prolonged time lag between determination of RNA sequence and structure. Accurate force fields can help fill this gap by reducing the amount of experimental data required to develop realistic structural models. Moreover, many RNAs are dynamic and simulations can provide predictions of dynamics. Because there are many parameters in a force field, confidence in simulations requires benchmarking against experimental characteristics of a wide variety of RNAs. 


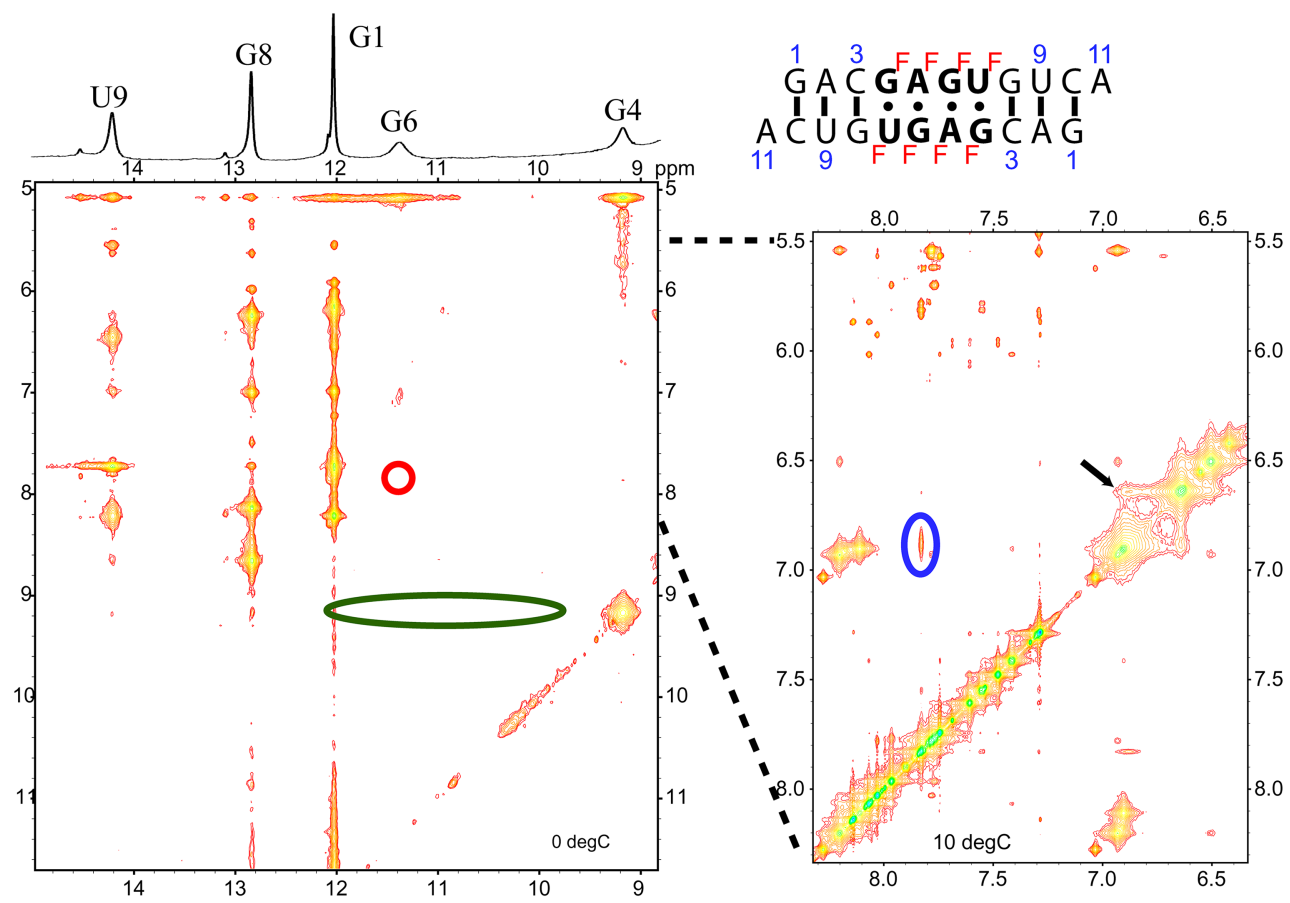

FIGURE 11. 2D NOESY spectra of $2^{\prime} \mathrm{F}$ : Residues $4-7$ have $2^{\prime}-\mathrm{OH}$ replaced with $2^{\prime} \mathrm{F}$. Temperature is $0^{\circ} \mathrm{C}$ with 50 msec mixing time in imino region spectrum (left) and $10^{\circ} \mathrm{C}$ with $100 \mathrm{msec}$ mixing time in aromatic region spectrum (right). Blue, red, and green circles correspond to NOE cross-peaks between protons indicated by arrows in Figure 7C and D. The black arrow indicates a strong cross-peak between G6 amino and A5* amino protons (see Fig. 7D).

In this work, the unusual major NMR (bulged) conformation (Fig. 3) of the RNA duplex with the (5'-GAGU$\left.3^{\prime}\right)_{2}$ internal loop (Kennedy et al. 2012) provided a novel test of the Amber ff99+ bsc0 + OL3 force field (Cornell et al. 1995; Cheatham et al. 1999; Pérez et al. 2007; Zgarbová et al. 2011; Case et al. 2012). This internal loop structure has stacked A's, GG H-bonded pairs, U's bulged out of the helix, and all sugars in a $\mathrm{C} 2^{\prime}$-endo conformation (Figs. 1-3; Table 2). This structure differs from NMR structures of internal loops, $\left(5^{\prime} \text {-GAGC- } 3^{\prime}\right)_{2},\left(5^{\prime} \text {-AAGU- } 3^{\prime}\right)_{2}$, and $\left(5^{\prime} \text {-UAGG- } 3^{\prime}\right)_{2}$, which have imino AG pairs flanked by canonical pairs and are maximally $\mathrm{H}$-bonded as shown in Figures 1-3 (Hammond et al. 2010). The internal loops studied here are therefore good tests of force fields because they explore performance on RNAs with different combinations of motifs that critically depend on a subtle balance of interactions.

Four 1- $\mu$ sec-long MD simulations were run on each of three duplexes in two starting conformations for a total of 24 simulations. Additionally, two $1-\mu$ sec simulations were run on the UAGG duplex starting with its NMR (maximally H-bonded) conformation. RMSD and 2D RMSD (Fig. 4; Supplemental Figs. S1-S3 in the Supplemental Material) were calculated to examine the predicted stability of different conformations. Clustering analysis (Table 3) and distribution of frames with respect to starting structures (Fig. 5) were also computed to determine the homogeneity of simulated structures. Additionally, interactions likely to stabilize the NMR conformation of the GAGU duplex (Tables 3, 4) were examined in detail.

For all four systems, Amber ff99 + bsc0 + OL3 accurately models the conformational preferences of all four loops, always giving lower average RMSD to the starting point for simulations starting from the NMR structure (Figs. 4, 5). Interactions in the NMR-derived model of the major (bulged) conformation of the $\left(5^{\prime} \text {-GAGU- } 3^{\prime}\right)_{2}$ loop were generally well preserved with the exception of the sugar pucker for G6/6* and the appearance of AA pairs in one simulation (Tables 3, 4). Likewise, duplexes with $\left(5^{\prime} \text {-GAGC- } 3^{\prime}\right)_{2},\left(5^{\prime}-\right.$ AAGU-3 $\left.3_{2}\right)_{2}$, and $\left(5^{\prime}-\mathrm{UAGG}-3^{\prime}\right)_{2}$ loops are stable in their NMR (maximally H-bonded) conformations (Table 4). The AAGU duplex showed a clear preference toward its NMR conformation as evidenced by an approximate $3 \AA$ higher RMSD to the starting structure when started in the alternative (bulged) conformation and by the set of multiple stable structures observed in the 2D RMSD plots (Fig. 4, panel B; Supplemental Fig. S3, panel C). The GAGC duplex showed a relatively stable alternative (bulged) conformation with RMSD about $1 \AA$ higher to the bulged starting structure as compared to when the simulation was started in the NMR (maximally paired) conformation. Evidently the identity of the bulged out base (C in GAGC vs. U in GAGU) does not play a part in short time stability of the bulged conformation (Figs. 4, 5). Either $\mathrm{C}$ or $\mathrm{U}$ could be locked into a bulged conformation. At equilibrium, however, NMR reveals that $\left(5^{\prime}-\right.$ GAGC- $\left.3^{\prime}\right)_{2}$ does not form a bulged structure. Presumably, 
this reflects the extra stability of a GC over a GU pair (see below).

While 1- $\mu$ sec simulations are too short for convergence, the stability of the (GACGAGUGUCA) $)_{2}$ duplex's NMR structure is in sharp contrast to the instability of duplex terminal base pairs and helical structure observed with Amber ff99 simulations. Evidently, the $\alpha / \gamma$ and $\chi$ revisions of $f f 99$ have improved the approximations of the forces driving RNA structure.

When simulations for the GAGU duplex were started with an alternative (maximally $\mathrm{H}$-bonded) internal loop structure of wobble GU and imino GA pairs, the loop rapidly switched to have reduced stacking overlap, changed $A G$ and $\mathrm{GU} H-$ bonds, and a narrow minor groove (Fig. 7). NMR data of the GAGU duplex minor conformation and of chemically modified sequences provide experimental evidence suggesting that this $\mathrm{G} 4 \& \mathrm{G} 6 \mathrm{NH}_{2} \mathrm{H}$-bonded loop is the dominant minor conformation of the GAGU duplex. Properties of this loop, specifically the bifurcated H-bond in the GU pair, the narrow minor groove, and all anti $\chi$ dihedrals with $\mathrm{C} 3^{\prime}$-endo sugars are found in the ribosome (G1002 and U966 in PDB ID: 1JJ2) in the context of a GU pair adjacent to a UU pair in an internal loop (Klein et al. 2001). Essentially the same $\mathrm{H}$-bonding pattern has also been modeled for NMR structures of the GU pairs in (GGCGUGCC) ${ }_{2}$ (Chen et al. 2000).

The secondary and NMR structures along with the MD simulations provide insight into reasons why the GAGU duplex has a unique shape. The GAGU duplex in its stable NMR (bulged) conformation and the GAGC and AAGU duplexes in unstable alternative (bulged) conformations have the same loop 3D shape. In the $\left(5^{\prime} \text {-GAGU- } 3^{\prime}\right)_{2}$ loop, a GG trans-WC/Hoogsteen base pair stabilizes this bulged conformation. On the basis of NMR, however, the duplexes with the $\left(5^{\prime} \text {-GAGC- } 3^{\prime}\right)_{2}$ and $\left(5^{\prime} \text {-AAGU-3' }\right)_{2}$ loops never form the bulged structure. Moreover, NMR and MD show that the tandem AG pairs of $\left(5^{\prime}-\mathrm{GAGC}-3^{\prime}\right)_{2}$ and $\left(5^{\prime}-\mathrm{AAGU}-3^{\prime}\right)_{2}$ are flanked by stable Watson-Crick pairs. In each case, the closing pair of the internal loop is preceded by a CG pair (see top of Fig. 3). At $0^{\circ} \mathrm{C}$, nearest neighbor $\Delta G^{\circ}$ parameters for $5^{\prime} \mathrm{CG} /$ $3^{\prime} \mathrm{GU}, 5^{\prime} \mathrm{CG} / 3^{\prime} \mathrm{GC}$, and $5^{\prime} \mathrm{CA} / 3^{\prime} \mathrm{GU}$ are, respectively, $-1.8 \pm$
$0.3,-3.3 \pm 0.3$, and $-3.1 \pm 0.2 \mathrm{kcal} / \mathrm{mol}$ (Xia et al. 1998; Chen et al. 2012). Because there are two such nearest neighbors in each duplex, these interactions for $5^{\prime} \mathrm{CG} / 3^{\prime} \mathrm{GU}$ loop closure are $3.0 \pm 0.8$ and $2.6 \pm 0.8 \mathrm{kcal} / \mathrm{mol}$, respectively, less favorable than closure by $5^{\prime} \mathrm{CG} / 3^{\prime} \mathrm{GC}$ and $5^{\prime} \mathrm{CA} / 3^{\prime} \mathrm{GU}$. Thus, it costs more to break the GC and AU pairs of $\left(5^{\prime}\right.$ CGAGCG-3 $\left.3_{2}\right)_{2}$ and $\left(5^{\prime} \text {-CAAGUG- } 3^{\prime}\right)_{2}$ to extrude the $\mathrm{C}$ or $\mathrm{U}$ bases into solvent than to extrude the U of ( $5^{\prime}$-CGAGUG$\left.3^{\prime}\right)_{2}$. In both the GAGU and AAGU duplexes, the $\mathrm{U}$ is in a GUG part of the sequence (Fig. 3). In $5^{\prime}$-GUG-3' single stranded trimer, the $\mathrm{U}$ is bulged out (Lee and Tinoco 1980; Lee 1983), similar to the $U$ in the NMR structure for the GAGU duplex (Fig. 3). However, in the (5'-GAGU-3' $)_{2}$ internal loop, a GG trans-WC/Hoogsteen base pair with two Hbonds stabilizes the bulged conformation. In contrast, as illustrated in Figure 12, the unstable AAGU bulged conformation replaces the GG pair with an AG pair that can form only a single $\mathrm{H}$-bond if pairing is isosteric with the GG pair (Leontis et al. 2002). This is reflected in higher RMSDs for simulations starting with the AAGU alternative (bulged) conformation (Fig. 4).

Given the range of hydrogen bonding and stacking interactions involved in the structures studied here, it is encouraging that the Amber $\mathrm{ff} 99+\mathrm{bsc} 0+\mathrm{OL} 3$ force field simulations agree with the structures previously determined by NMR. For example, the simulations reproduce the two GG pairs with all Gs in a syn conformation as found in the NMR (bulged) structure of the GAGU duplex (Kennedy et al. 2012). Known structures rarely contain base pairs formed by two syn bases (Leontis and Westhof 2001). Additionally, the simulations predicted an unexpected minor conformation for $\left(5^{\prime}-\text { GAGU- } 3^{\prime}\right)_{2}$ that is consistent with new NMR spectra. Simulations on other systems, however, have sometimes been successful (Spasic et al. 2012; Aytenfisu et al. 2014) and sometimes not (Banáś et al. 2010; Bergonzo et al. 2014, 2015; Condon et al. 2015; Zgarbová et al. 2017). In general, recent progress (Smith et al. 2017; Šponer et al. 2017) reinforces the promise of physics-based approaches for development of force fields for RNA and other polymers.

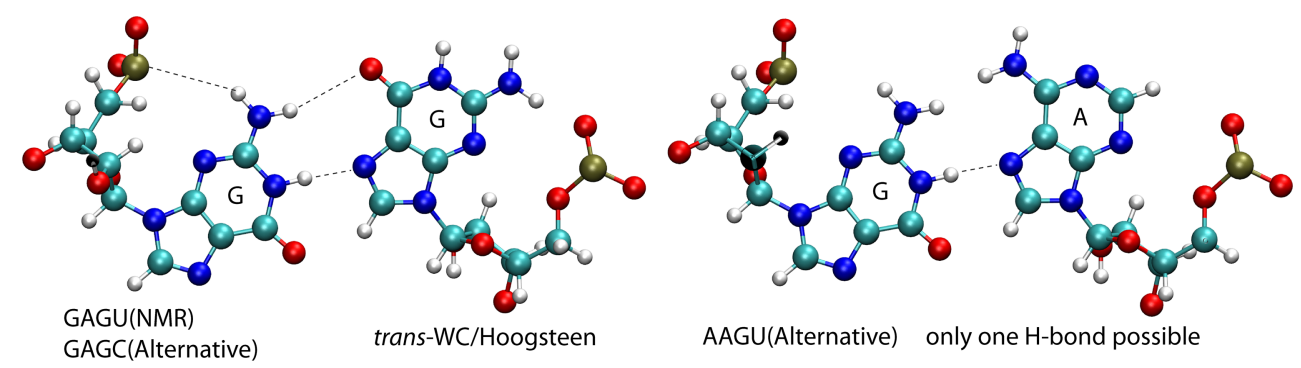

FIGURE 12. Comparison of nucleotides in the loop region. In the GAGU NMR and GAGC alternative conformation (which both have the same loop region), two structure stabilizing trans-Watson-Crick/Hoogsteen H-bonds are formed (left base pair). In the AAGU alternative conformation, G is replaced with A and only one hydrogen bond is possible. 


\section{MATERIALS AND METHODS}

\section{Starting structures}

Atomic coordinates for the duplexes with internal closing base pair/ loop combinations, $\left(5^{\prime}-\mathrm{GAGU}-3^{\prime}\right)_{2},\left(5^{\prime} \text {-GAGC- } 3^{\prime}\right)_{2},\left(5^{\prime}\right.$-AAGU$\left.3^{\prime}\right)_{2}$, and $\left(5^{\prime} \text {-UAGG- } 3^{\prime}\right)_{2}$, were taken from their respective NMR structures, 2LX1 (Kennedy et al. 2012), 2KY0, 2KXZ, and 2KY2 (Hammond et al. 2010). In each case, the conformation with the least NMR restraint violations, as indicated in the coordinate files, was used in simulations.

\section{Creating alternative conformations}

Alternative conformations (Fig. 3) were created for GAGU, GAGC, and AAGU duplexes. Because they all have a central 5'AG3' sequence, the alternative conformations were created (in silico) by mutating the closing nucleotides. For example, the alternative conformation for the GAGU sequence was created from the AAGU sequence by mutating the $5^{\prime}$-end loop-closing $A$ into $G$ on both strands. Similarly, the alternative conformation for the GAGC duplex was obtained from the major GAGU duplex structure (2LX1) by mutating the $3^{\prime}$-end loop-closing $\mathrm{U}$ to $\mathrm{C}$. Because mutating purine to purine and pyrimidine to pyrimidine involved changing only a few atoms, the effect on the conformation of the molecule is minimal. The duplex with the UAGG sequence had a shorter total strand length and different base pair composition in addition to having pyrimidines replacing the purines and vice versa at the base pairs closing the helix. Therefore, the duplex with the UAGG sequence was simulated only starting in its NMR conformation.

\section{MD simulations}

All MD simulations were run with the same protocol. First, a duplex was immersed in a truncated octahedron box filled with TIP3P water models (Jorgensen et al. 1983) such that there is at least $10 \AA$ of water from each side of the molecule. Enough $\mathrm{Na}^{+}$ions were added to neutralize the RNA charge. Based on the volume of the water box, enough $\mathrm{Na}^{+}$and $\mathrm{Cl}^{-}$ions were then added to obtain a $0.1 \mathrm{M} \mathrm{NaCl}$ concentration, which is similar to NMR conditions. Systems were then energy minimized in two 1000 step stages. First, the solute molecule was held fixed and only water molecules were minimized.

Second, the whole system was allowed to equilibrate. The system was then heated from 0 to $300 \mathrm{~K}$ over 50 psec using a Langevin thermostat (Chandrasekhar 1943) with $1 \mathrm{psec}^{-1}$ frequency of collision. In the final stage of equilibration, Berendsen pressure regulation (Berendsen et al. 1984) with isotropic position scaling was turned on and the system equilibrated for $1 \mathrm{nsec}$ at pressure of $1 \mathrm{~atm}$. Finally, production simulations were run at $300 \mathrm{~K}$ and $1 \mathrm{~atm}$ (NPT ensemble). Bonds to hydrogens were constrained with the SHAKE algorithm (Ryckaert et al. 1977), which allowed for a 2 fsec time step. Simulations were run with the graphical card implementation (Salomon-Ferrer et al. 2013) of the molecular dynamics engine of the Amber 12 software package (Case et al. 2012). All molecules were modeled with the Amber ff $99+$ bsc $0+$ OL3 force field for RNAs. This force field contains the original parameters from force fields ff94 (Cornell et al. 1995) and ff99 (Cheatham et al. 1999; Wang et al. 2000) along with corrections for $\alpha$ and $\gamma$ backbone dihedrals (Pérez et al. 2007) and glycosidic dihedrals for all four bases (Zgarbová et al. 2011). Each duplex was simulated in four independent simulations for $1 \mu \mathrm{sec}$, except for the UAGG duplex for which two simulations were run. In addition, two 1- $\mu$ sec simulations were run for the GAGU duplex in its NMR (bulged) and alternative conformation using the older ff9 9 force field. The total simulation time for all duplexes was $30 \mu \mathrm{sec}$.

\section{Analysis of MD results}

Distances, angles, dihedrals, root-mean-square displacement (RMSD), and two-dimensional RMSD were calculated using the cpptraj module of the Amber software package (Roe and Cheatham 2013). When calculating the RMSD of the loop region of bulged conformations, the bulged nucleotides (U7 and U7* in GAGU and AAGU duplexes and $\mathrm{C} 7$ and $\mathrm{C}^{*}$ in GAGC duplex) were left out.

\section{Clustering of trajectories}

Clustering was performed on the combined trajectories of all four internal loop duplexes run starting from NMR conformation or alternative conformation. The dbscan clustering algorithm (Ester et al. 1996) was used as implemented in the cpptraj module (Roe and Cheatham 2013) of Amber. Clustering was performed such that the minimum distance between points required for forming a cluster was $1.8 \AA$ and the minimum number of points required for forming a cluster was 40 . Dbscan also reports the percentage of noise frames, i.e., frames that do not belong to any of the clusters. This quantity is in the third column of Table 3.

\section{NMR experiments and modeling}

NMR spectra of modified RNAs were acquired with Varian Inova 600 and $500 \mathrm{MHz}$ spectrometers as previously described for unmodified RNA (Hammond et al. 2010; Kennedy et al. 2012). RNA strand concentrations ranged from about 0.9 to $2.4 \mathrm{mM}$. All samples were in the same buffer: $20 \mathrm{mM}$ sodium phosphate, $0.5 \mathrm{mM}$ $\mathrm{Na}_{2}$ EDTA, $80 \mathrm{mM} \mathrm{NaCl}, \mathrm{pH}$ 6.1. Previously published structures were modeled from spectra taken at 270 to $288 \mathrm{~K}$. Imino proton spectra, however, showed little or no change in chemical shifts up to $288 \mathrm{~K}$ for (GACGAGUGUCA) $2,293 \mathrm{~K}$ for (GACAAGUG $\mathrm{UCA})_{2}$, and $303 \mathrm{~K}$ for (GACGAGCGUCA) ${ }_{2}$ (Hammond et al. 2010; Kennedy et al. 2012).

\section{Chemical synthesis of oligonucleotides}

Oligonucleotides with inosine or LNA were synthesized using standard phosphoramidite chemistry (Beaucage and Caruthers 1981) with commercially available RNA and LNA phosphoramidites (GenePharma, Exiqon). Oligonucleotides were deprotected and purified as described previously (Xia et al. 1998; Kierzek and Kierzek 2003) and characterized using MALDI-TOF mass spectrometry. The 2'F oligonucleotide was synthesized with a previously reported method (Manoharan et al. 2011).

\section{SUPPLEMENTAL MATERIAL}

Supplemental material is available for this article. 


\section{ACKNOWLEDGMENTS}

This work was supported by National Institutes of Health (National Institute of General Medical Sciences) grants R01GM076485 to D.H.M. and R01GM22939 to D.H.T., and a grant from the National Science Center, UMO-2013/08/A/ST5/00295, to R.K.

Received October 17, 2017; accepted January 19, 2018.

\section{REFERENCES}

Adams PL, Stahley MR, Gill ML, Kosek AB, Wang J, Strobel SA. 2004. Crystal structure of a group I intron splicing intermediate. RNA 10: $1867-1887$.

Altman S. 2007. A view of RNase P. Mol Biosyst 3: 604-607.

Amunts A, Brown A, Bai X, Llácer JL, Hussain T, Emsley P, Long F, Murshudov G, Scheres SHW, Ramakrishnan V. 2014. Structure of the yeast mitochondrial large ribosomal subunit. Science 343: $1485-1489$.

Atkins JF, Gesteland RF, Cech TR. 2011. RNA Worlds. Cold Spring Harbor Laboratory Press, Cold Spring Harbor, New York.

Aytenfisu AH, Spasic A, Seetin MG, Serafini J, Mathews DH. 2014. Modified amber force field correctly models the conformational preference for tandem GA pairs in RNA. J Chem Theory Comput 10: 1292-1301.

Ban N, Nissen P, Hansen J, Moore PB, Steitz TA. 2000. The complete atomic structure of the large ribosomal subunit at $2.4 \AA$ resolution. Science 289: 905-920.

Banáš P, Hollas D, Zgarbová M, Jurečka P, Orozco M, Cheatham TE, Šponer J, Otyepka M. 2010. Performance of molecular mechanics force fields for RNA simulations: stability of UUCG and GNRA hairpins. J Chem Theory Comput 6: 3836-3849.

Beaucage SL, Caruthers MH. 1981. Deoxynucleoside phosphoramidites - a new class of key intermediates for deoxypolynucleotide synthesis. Tetrahedron Lett 22: 1859-1862.

Berendsen HJC, Postma JPM, van Gunsteren WF, DiNola A, Haak JR. 1984. Molecular dynamics with coupling to an external bath. J Chem Phys 81: 3684-3690.

Bergonzo C, Henriksen NM, Roe DR, Swails JM, Roitberg AE, Cheatham TE III. 2014. Multidimensional replica exchange molecular dynamics yields a converged ensemble of an RNA tetranucleotide. J Chem Theory Comput 10: 492-499.

Bergonzo C, Henriksen NM, Roe DR, Cheatham TE III. 2015. Highly sampled tetranucleotide and tetraloop motifs enable evaluation of common RNA force fields. RNA 21: 1578-1590.

Case DA, Darden TE, Cheatham TE III, Simmerling CL, Wang J, Duke RE, Luo R, Walker RC, Zhang W, Merz KM, et al. 2012. AMBER 12. University of California, San Francisco.

Cate JH, Gooding AR, Podell E, Zhou K, Golden BL, Kundrot CE, Cech TR, Doudna JA. 1996. Crystal structure of a group I ribozyme domain: principles of RNA packing. Science 273: 1678-1685.

Chan RT, Robart AR, Rajashankar KR, Pyle AM, Toor N. 2012. Crystal structure of a group II intron in the pre-catalytic state. Nat Struct Mol Biol 19: 555-557.

Chandrasekhar S. 1943. Stochastic problems in physics and astronomy. Rev Mod Phys 15: 1-89.

Cheatham TE III, Cieplak P, Kollman PA. 1999. A modified version of the Cornell et al. force field with improved sugar pucker phases and helical repeat. J Biomol Struct Dyn 16: 845-862.

Chen X, McDowell JA, Kierzek R, Krugh TR, Turner DH. 2000. Nuclear magnetic resonance and molecular modeling reveal that different hydrogen bonding patterns are possible for G.U pairs: one hydrogen bond for each G.U pair in r(GGCGUGCC) $)_{2}$ and two for each G.U pair in $\mathrm{r}$ (GAGUGCUC) $)_{2}$. Biochemistry 39: 8970-8982.

Chen JL, Dishler AL, Kennedy SD, Yildirim I, Liu B, Turner DH, Serra MJ. 2012. Testing the nearest neighbor model for canonical
RNA base pairs: revision of GU parameters. Biochemistry 51: 3508-3522.

Chen JL, Kennedy SD, Turner DH. 2015. Structural features of a $3^{\prime}$ splice site in influenza A. Biochemistry 54: 3269-3285.

Christiansen ME, Znosko BM. 2008. Thermodynamic characterization of the complete set of sequence symmetric tandem mismatches in RNA and an improved model for predicting the free energy contribution of sequence asymmetric tandem mismatches. Biochemistry 47: 4329-4336.

Condon DE, Kennedy SD, Mort BC, Kierzek R, Yildirim I, Turner DH. 2015. Stacking in RNA: NMR of four tetramers benchmark molecular dynamics. J Chem Theory Comput 11: 2729-2742.

Cornell WD, Cieplak P, Bayly CI, Gould IR, Merz KM, Ferguson DM, Spellmeyer DC, Fox T, Caldwell JW, Kollman PA. 1995. A second generation force field for the simulation of proteins, nucleic acids, and organic molecules. J Am Chem Soc 117: 5179-5197.

Doudna JA, Cech TR. 2002. The chemical repertoire of natural ribozymes. Nature 418: 222-228.

Eddy SR. 2001. Non-coding RNA genes and the modern RNA world. Nat Rev Genet 2: 919-929.

Ester M, Kriegel HP, Sander J, Xu X. 1996. A density-based algorithm for discovering clusters in large spatial databases with noise. In Second international conference on knowledge discovery and data mining, pp. 226-231. AAAI Press, München, Germany.

Hammond NB, Tolbert BS, Kierzek R, Turner DH, Kennedy SD. 2010. RNA internal loops with tandem AG pairs: the structure of the $5^{\prime}$ GAGU/3'UGAG loop can be dramatically different from others, including 5'AAGU/3'UGAA. Biochemistry 49: 5817-5827.

Heus HA, Wijmenga SS, Hoppe H, Hilbers CW. 1997. The detailed structure of tandem G.A mismatched base-pair motifs in RNA duplexes is context dependent. J Mol Biol 271: 147-158.

Jeener J, Meier BH, Bachmann P, Ernst RR. 1979. Investigation of exchange processes by two-dimensional NMR spectroscopy. J Chem Phys 71: 4546-4553.

Johnston PD, Redfield AG. 1981. Nuclear magnetic resonance and nuclear Overhauser effect study of yeast phenylalanine transfer ribonucleic acid imino protons. Biochemistry 20: 1147-1156.

Jorgensen WL, Chandrasekhar J, Madura JD, Impey RW, Klein ML. 1983. Comparison of simple potential functions for simulating liquid water. J Chem Phys 79: 926-935.

Kennedy SD, Kierzek R, Turner DH. 2012. Novel conformation of an RNA structural switch. Biochemistry 51: 9257-9259.

Kierzek E, Kierzek R. 2003. The synthesis of oligoribonucleotides containing $N^{6}$-alkyladenosines and 2 -methylthio- $N^{6}$-alkyladenosines via post-synthetic modification of precursor oligomers. Nucleic Acids Res 31: 4461-4471.

Klein DJ, Schmeing TM, Moore PB, Steitz TA. 2001. The kink-turn: a new RNA secondary structure motif. EMBO J 20: 4214-4221.

Lee CH. 1983. Conformational studies of 13 trinucleoside bisphosphates by $360-\mathrm{MHz}$ 1H-NMR spectroscopy. Eur J Biochem 137: 347-356.

Lee CH, Tinoco I Jr. 1980. Conformation studies of 13 trinucleoside diphosphates by $360 \mathrm{MHz}$ PMR spectroscopy. A bulged base conformation: I. Base protons and $\mathrm{H1}^{\prime}$ protons. Biophys Chem 11: 283-294.

Leontis NB, Westhof E. 2001. Geometric nomenclature and classification of RNA base pairs. RNA 7: 499-512.

Leontis NB, Stombaugh J, Westhof E. 2002. The non-Watson-Crick base pairs and their associated isostericity matrices. Nucleic Acids Res 30: 3497-3531.

Manoharan M, Akinc A, Pandey RK, Qin J, Hadwiger P, John M, Mills K, Charisse K, Maier MA, Nechev L, et al. 2011. Unique gene-silencing and structural properties of $2^{\prime}$-fluoro-modified siRNAs. Angew Chem Int Ed Engl 50: 2284-2288.

Marcia M, Pyle AM. 2012. Visualizing group II intron catalysis through the stages of splicing. Cell 151: 497-507.

Miao Z, Adamiak RW, Blanchet MF, Boniecki M, Bujnicki JM, Chen SJ, Cheng C, Chojnowski G, Chou FC, Cordero P, et al. 2015. RNAPuzzles Round II: assessment of RNA structure prediction programs applied to three large RNA structures. RNA 21: 1066-1084. 
Miao Z, Adamiak RW, Antczak M, Batey RT, Becka AJ, Biesiada M, Boniecki MJ, Bujnicki JM, Chen SJ, Cheng CY, et al. 2017. RNAPuzzles Round III: 3D RNA structure prediction of five riboswitches and one ribozyme. RNA 23: 655-672.

Morgado CA, Svozil D, Turner DH, Šponer J. 2012. Understanding the role of base stacking in nucleic acids. MD and QM analysis of tandem GA base pairs in RNA duplexes. Phys Chem Chem Phys 14: 12580-12591.

Pan B, Mitra SN, Sun L, Hart D, Sundaralingam M. 1998. Crystal structure of an RNA octamer duplex r(CCCIUGGG) $)_{2}$ incorporating tandem I.U wobbles. Nucleic Acids Res 26: 5699-5706.

Pérez A, Marchán I, Svozil D, Sponer J, Cheatham TE, Laughton CA, Orozco M. 2007. Refinement of the AMBER force field for nucleic acids: improving the description of $\alpha / \gamma$ conformers. Biophys $J$ 92: 3817-3829.

Peterson RD, Bartel DP, Szostak JW, Horvath SJ, Feigon J. 1994. 1H NMR studies of the high-affinity Rev binding site of the Rev responsive element of HIV-1 mRNA: base pairing in the core binding element. Biochemistry 33: 5357-5366.

Pley HW, Flaherty KM, McKay DB. 1994. Three-dimensional structure of a hammerhead ribozyme. Nature 372: 68-74.

Popenda M, Szachniuk M, Blazewicz M, Wasik S, Burke EK, Blazewicz J, Adamiak RW. 2010. RNA FRABASE 2.0: an advanced web-accessible database with the capacity to search the three-dimensional fragments within RNA structures. BMC Bioinformatics 11: 231.

Roe DR, Cheatham TE. 2013. PTRAJ and CPPTRAJ: software for processing and analysis of molecular dynamics trajectory data. J Chem Theory Comput 9: 3084-3095.

Ryckaert JP, Ciccotti G, Berendsen HJC. 1977. Numerical integration of the cartesian equations of motion of a system with constraints: molecular dynamics of $n$-alkanes. J Comput Phys 23: 327-341.

Salomon-Ferrer R, Götz AW, Poole D, Le Grand S, Walker RC. 2013. Routine microsecond molecular dynamics simulations with AMBER on GPUs. 2. Explicit solvent particle mesh Ewald. J Chem Theory Comput 9: 3878-3888.

Santa Lucia J, Turner DH. 1993. Structure of (rGGCGAGCC) ${ }_{2}$ in solution from NMR and restrained molecular dynamics. Biochemistry 32: $12612-12623$

Serganov A, Patel DJ. 2007. Ribozymes, riboswitches and beyond: regulation of gene expression without proteins. Nat Rev Genet 8: 776-790.

Simon B, Masiewicz P, Ephrussi A, Carlomagno T. 2015. The structure of the SOLE element of oskar mRNA. RNA 21: 1444-1453.

Smith LG, Zhao J, Mathews DH, Turner DH. 2017. Physics-based allatom modeling of RNA energetics and structure. Wiley Interdiscip Rev RNA 8. doi: 10.1002/wrna.1422.

Spasic A, Serafini J, Mathews DH. 2012. The Amber ff99 force field predicts relative free energy changes for RNA helix formation. J Chem Theory Comput 8: 2497-2505.

Šponer J, Krepl M, Banáś $\mathrm{P}$, Kührová $\mathrm{P}$, Zgarbová $\mathrm{M}$, Jurečka $\mathrm{P}$, Havrila M, Otyepka M. 2017. How to understand atomistic molecular dynamics simulations of RNA and protein-RNA complexes? Wiley Interdiscip Rev RNA 8. doi: 10.1002/wrna.1405.
Tolbert BS, Kennedy SD, Schroeder SJ, Krugh TR, Turner DH. 2007. NMR structures of (rGCUGAGGCU) $)_{2}$ and (rGCGGAUGCU) ${ }_{2}$ : probing the structural features that shape the thermodynamic stability of GA pairs. Biochemistry 46: 1511-1522.

Turner DH, Sugimoto N, Kierzek R, Dreiker SD. 1987. Free energy increments for hydrogen bonds in nucleic acid base pairs. J Am Chem Soc 109: 3783-3785.

Verschoor A, Warner JR, Srivastava S, Grassucci RA, Frank J. 1998. Three-dimensional structure of the yeast ribosome. Nucleic Acids Res 26: 655-661.

Vester B, Wengel J. 2004. LNA (locked nucleic acid): high-affinity targeting of complementary RNA and DNA. Biochemistry 43: 13233-13241.

Wang J, Cieplak P, Kollman PA. 2000. How well does a restrained electrostatic potential (RESP) model perform in calculating conformational energies of organic and biological molecules? J Comput Chem 21: 1049-1074.

Wright DJ, Rice JL, Yanker DM, Znosko BM. 2007. Nearest neighbor parameters for inosine uridine pairs in RNA duplexes. Biochemistry 46: 4625-4634.

Wu L, Belasco JG. 2008. Let me count the ways: mechanisms of gene regulation by miRNAs and siRNAs. Mol Cell 29: 1-7.

Wu M, Turner DH. 1996. Solution structure of (rGCGGACGC) $)_{2}$ by two-dimensional NMR and the iterative relaxation matrix approach. Biochemistry 35: 9677-9689.

Wu M, SantaLucia J Jr, Turner DH. 1997. Solution structure of (rGGCAGGCC) ${ }_{2}$ by two-dimensional NMR and the iterative relaxation matrix approach. Biochemistry 36: 4449-4460.

Xia T, SantaLucia J Jr, Burkard ME, Kierzek R, Schroeder SJ, Jiao X, Cox C, Turner DH. 1998. Thermodynamic parameters for an expanded nearest-neighbor model for formation of RNA duplexes with Watson-Crick base pairs. Biochemistry 37: 14719-14735.

Yildirim I, Stern HA, Sponer J, Spackova N, Turner DH. 2009. Effects of restrained sampling space and nonplanar amino groups on free-energy predictions for RNA with imino and sheared tandem GA base pairs flanked by GC, CG, iGiC or iCiG base pairs. J Chem Theory Comput 5: 2088-2100.

Yusupov MM, Yusupova GZ, Baucom A, Lieberman K, Earnest TN, Cate JHD, Noller HF. 2001. Crystal structure of the ribosome at 5.5 Å resolution. Science 292: 883-896.

Zgarbová M, Otyepka M, Sponer J, Mládek A, Banáš P, Cheatham TE, Jurečka P. 2011. Refinement of the Cornell et al. nucleic acids force field based on reference quantum chemical calculations of glycosidic torsion profiles. J Chem Theory Comput 7: 2886-2902.

Zgarbová M, Jurečka P, Banáš P, Havrila M, Šponer J, Otyepka M. 2017. Noncanonical $\alpha / \gamma$ backbone conformations in RNA and the accuracy of their description by the AMBER force field. J Phys Chem B 121: 2420-2433.

Zhao C, Rajashankar KR, Marcia M, Pyle AM. 2015. Crystal structure of group II intron domain 1 reveals a template for RNA assembly. Nat Chem Biol 11: 967-972. 

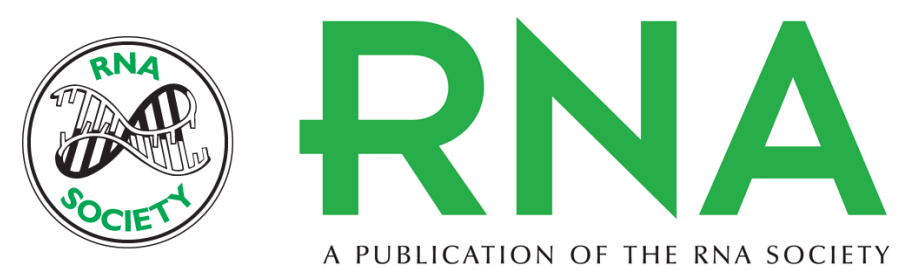

\section{Molecular dynamics correctly models the unusual major conformation of the GAGU RNA internal loop and with NMR reveals an unusual minor conformation}

Aleksandar Spasic, Scott D. Kennedy, Laura Needham, et al.

RNA 2018 24: 656-672 originally published online February 6, 2018

Access the most recent version at doi:10.1261/rna.064527.117

Supplemental Material

References

Creative Commons License

Email Alerting Service
http://rnajournal.cshlp.org/content/suppl/2018/02/06/rna.064527.117.DC1

This article cites 68 articles, 11 of which can be accessed free at: http://rnajournal.cshlp.org/content/24/5/656.full.html\#ref-list-1

This article is distributed exclusively by the RNA Society for the first 12 months after the full-issue publication date (see http://rnajournal.cshlp.org/site/misc/terms.xhtml). After 12 months, it is available under a Creative Commons License (Attribution-NonCommercial 4.0 International), as described at http://creativecommons.org/licenses/by-nc/4.0/.

Receive free email alerts when new articles cite this article - sign up in the box at the top right corner of the article or click here.

To subscribe to RNA go to:

http://rnajournal.cshlp.org/subscriptions 